Review

\title{
Review on Non-Volatile Memory with High- $k$ Dielectrics: Flash for Generation Beyond 32 nm
}

\author{
Chun Zhao ${ }^{1}$, Ce Zhou Zhao ${ }^{1,2, *}$, Stephen Taylor ${ }^{1}$ and Paul R. Chalker ${ }^{3}$
}

1 Department of Electrical Engineering and Electronics, University of Liverpool, Liverpool L69 3GJ, UK; E-Mails: chun.zhao@liverpool.ac.uk (C.Z.); s.taylor@liverpool.ac.uk (S.T.)

2 Department of Electrical and Electronic Engineering, Xi'an Jiaotong-Liverpool University, Suzhou 215123, China

3 Department of Materials Science and Engineering, University of Liverpool, Liverpool L69 3GH, UK; E-Mail: pchalker@liverpool.ac.uk

* Author to whom correspondence should be addressed; E-Mail: cezhou.zhao@xjtlu.edu.cn; Tel.: +86-512-8816-1408.

Received: 15 January 2014; in revised form: 2 July 2014 / Accepted: 3 July 2014 /

Published: 15 July 2014

\begin{abstract}
Flash memory is the most widely used non-volatile memory device nowadays. In order to keep up with the demand for increased memory capacities, flash memory has been continuously scaled to smaller and smaller dimensions. The main benefits of down-scaling cell size and increasing integration are that they enable lower manufacturing cost as well as higher performance. Charge trapping memory is regarded as one of the most promising flash memory technologies as further down-scaling continues. In addition, more and more exploration is investigated with high- $k$ dielectrics implemented in the charge trapping memory. The paper reviews the advanced research status concerning charge trapping memory with high- $k$ dielectrics for the performance improvement. Application of high- $k$ dielectric as charge trapping layer, blocking layer, and tunneling layer is comprehensively discussed accordingly.
\end{abstract}

Keywords: non-volatile memory; flash; high- $k$ dielectrics; charge trapping memory 


\section{Introduction}

A non-volatile memory device is one that can retain stored information in the absence of power and flash memory is a type of non-volatile memory [1]. Floating-gate flash memory has been successfully developed in the last few decades with continues down-scaling the dimensions of the cell to obtain high data-storage density, high program/erase speeds, low operating voltage and low power consumption [2]. The ever-increasing fabrication density of Flash memory has been mainly driven by area scaling [3]. However, some intrinsic limitations make this type of memory rapidly approach the scaling limit. As Flash memory device scales down beyond the $32 \mathrm{~nm}$ technology node, approaches face significant challenges. A relatively thick tunneling oxide and inter poly dielectric layer have to be used in the floating-gate memory to maintain acceptable reliability, limiting further down-scaling of the cell size in the vertical direction [4]. In addition, maintaining a high gate coupling ratio is still one main bottle-neck for down-scaling the floating-gate devices [5]. Moreover, as the spacing between adjacent devices is down-scaled, this parasitic capacitance plays an increasingly dominant role in the device performance due to data stored in the adjacent cells can interfere with each other by capacitive coupling [6]. Additionally, a limited margin poses a great challenge on the reliability of the floating-gate memory devices, as the number of electrons stored in floating-gate significantly decreases with continual down-scaling of the cell size [7].

Some promising memory technologies have been developed for the next-generation flash memory to go beyond the current floating-gate flash memory technology. The ferroelectric field effect transistor (FeFET) is a one transistor (1T) memory device where a ferroelectric capacitor is integrated into the gate stack of a FET [8]. The ferroelectric polarization directly affects charges in the channel and leads to a defined shift of the output characteristics of the FET. At the channel interface, a high quality insulator is required to guarantee a low interface state density. For this reason it is very difficult to fabricate a FeFET with excellent electrical properties. Scaling is projected to end approximately with the $22 \mathrm{~nm}$ generation, because the insulation layer becomes too thin and the properties of the ferroelectric with respect to thickness dependence of the coercive field will not allow further reduction [9]. In addition, the major challenge is the long-term reliability related to the ferroelectric-semiconductor interface. Another important challenge is the rather short retention time, approximately 30 days, for the FeFET. The nanoelectromechanical memory (NEMM) is based on a bi-stable nano-electromechanical switch [10]. In this concept, mechanical digital signals are represented by displacements of solid nanoelements, which result in closing or opening an electrical circuit. Several different modifications of suspended-beam NEMMs are currently being explored using different materials including carbon nanotubes, Si, Ge, and TiN. A difficult challenge of the suspended-beam NEMM is scalabily: according to a recent study, it might be difficult to achieve low-voltage $(\sim 1 \mathrm{~V})$ operation for the beam length less than $50 \mathrm{~nm}$ [11]. The spin transfer torque memory (STTRAM) is an advanced version of the magnetic RAM with a different write mechanism [12]. The memory cell consists of a semiconductor isolation device and a magnetic tunnel junction with two ferromagnetic layers separated by a MgO-based tunneling barrier layer in which thickness is controlled to approximately $1 \mathrm{~nm}$. Key factors in STTRAM development include reducing STT writing current and voltage (energy) while maintaining adequate thermal stability. In nanothermal memory elements, consisting of a nano-scale metal-insulator-metal (MIM) structure, typical resistive switching phenomena are based on thermal 
effects, which result in unipolar switching characteristics [13]. The other type of nanothermal memory is nanowire-structured phase change cell, for which the underlying phase transformation between amorphous and crystalline phases is similar to the conventional phase-change memory (PCM) [14]. Compared to prototypical PCM, the switching current and therefore the write energy could be considerably reduced in nanowire-PCM cells. The principle challenge is fabrication of the nanowire crossbar memory cells containing the required select diodes, perhaps using self-assembly or directed-assembly technology. The nanoionic memory operation is based on a change in resistance of a MIM structure caused by ion (cation or anion) migration combined with redox processes involving the electrode material or the insulator material, or both [15]. Precise predictions are not yet possible, because many details of the mechanism of the reported phenomena are still unknown. Developing an understanding of the physical mechanisms governing switching of the nanoionic memory is a key challenge for this technology. Macromolecular memory sometimes referred to as polymer or organic memory consists of a memory element, which is a thin-film of organic material [16]. It is, in some cases, similar to molecular memory, but extreme scaling is not important, while reduced fabrication cost is emphasized. Charge-trapping memory (CTM) was firstly introduced in 1967 to show some distinguished advantages over the conventional floating-gate counterpart [17]. It defines the program/erase states via adding charges to and removing charges from the charge-storage layer respectively, similar to floating-gate memory. Apart from the floating-gate cell where charges are mainly stored in the conduction band of the floating gate, the main difference of charge-trapping flash memory is that charges are located at the spatially discrete traps distributed in the band-gap of the charge-trapping layer. CTM is totally compatible with the complementary metal-oxide-semiconductor (CMOS) technology, and easy to be integrated with current fabrication process.

NOR-type CTM flash memories were the first to be introduced towards the scaling for two decades. Until recently, non-volatile memory half-pitches have lagged behind those for dynamic random access memory (DRAM) or CMOS logic devices in the same year [18]. Rapid progress in NAND CTM flash technology has not only reversed this trend, but also surpassed the half-pitches of DRAM and CMOS logic devices. NAND flash memories have seen tremendous demand in this decade. Both NOR and NAND flash memories are now facing major roadblocks in continued scaling. NOR flash memory devices are programmed by channel hot-electron injection. Since the silicon-oxide barrier height is $3.2 \mathrm{eV}$, the drain voltage has to be at least greater than $3.2 \mathrm{~V}$ for reasonable efficiency. Therefore, there is a major challenge in scaling the drain voltage in NOR flash devices [19]. The scaling of tunnel oxide is limited by concerns for reliability issues. As NOR flash memories provide direct cell access, the reliability issues are more stringent, unlike NAND flash memories which can use error code correction and data re-mapping strategies. The tunnel oxide thickness for NOR flash devices is essentially stuck at $8-9 \mathrm{~nm}$ and not scaled anymore. There are a number of factors contributing to difficulty in scaling channel length in NOR flash devices. The tunnel oxide does not scale anymore, because a thinner tunnel oxide reduces short-channel effects. Hence, the channel length faces potentially game-ending scaling issues and consequently, so does the cell area. As for NAND flash memory, the scaling of high-density is limited by parasitic interference between adjacent cells since they are extremely close to each other. The charge trapping layer (CTL), being a capacitive-coupled electrode, has started to have significant coupling with the charge trapping layer of adjacent cells and other electrodes of neighboring cells. This causes an undesirable shift in the state of one cell due to neighboring cells. 
Like NOR flash, tunnel oxide scaling in NAND flash is also limited by reliability concerns. The tunnel oxide thickness is stuck at $\sim 6 \mathrm{~nm}$ and needs breakthroughs to continue scaling beyond that. The control dielectric thickness is also limited by reliability concerns, similar to the tunnel oxide. Reliability concerns are also very serious if the control dielectric is modified to use high- $k$ dielectrics, which may be necessary to improve gate coupling ratio. The ultimate intrinsic limits of NAND flash memories are likely to be due to statistical fluctuations induced by too few electrons stored. The International Technology Roadmap for Semiconductors (ITRS) scaling projection for floating-gate NOR and NAND flash is shown comprehensively in the following tables (Tables 1 and 2). Nowadays, high- $k$ dielectrics [20-32] are highly considered and widely implemented for CTM upon continually scaling down of the dimensions of flash memory [33]. The advantage of using high- $k$ dielectrics is that for the same equivalent oxide thickness (EOT), the high- $k$ dielectrics can have a thicker physical thickness than silicon dioxides. The using of high- $k$ dielectrics makes it possible for continual down-scaling of the cell size.

In the paper, the CTM with high- $k$ dielectrics are reviewed. Firstly, the characterization of CTM is introduced. Then, concerning high- $k$ dielectrics as the core of CTM: charge trapping layer, much more efforts are focused within the paper. Afterwards, the paper briefly reviews some high- $k$ dielectric application as blocking and tunneling layer associated with CTM for alternative option to replace thermal oxides, despite reliability concerns might be a very serious issue if the tunneling dielectric is modified to use high- $k$ dielectrics. Finally, conclusion in the end gives a summary of this research work, also provides a research direction for the next-generation flash memory.

Table 1. International Technology Roadmap for Semiconductors (ITRS) Scaling projections for floating-gate NOR flash [18].

\begin{tabular}{lcccccc}
\hline NOR flash & $\mathbf{2 0 0 9}$ & $\mathbf{2 0 1 0}$ & $\mathbf{2 0 1 1}$ & $\mathbf{2 0 1 2}$ & $\mathbf{2 0 1 3}$ & $\mathbf{2 0 1 4}$ \\
\hline NOR flash technology node $-F(\mathrm{~nm})[21]$ & 50 & 45 & 40 & 35 & 32 & 28 \\
A. floating gate NOR flash & & & & & & \\
Cell size-area factor in a multiples of $F^{2}[22-25]$ & $9-11$ & $9-11$ & $9-11$ & $9-11$ & $9-11$ & $9-11$ \\
Gate length $L_{\mathrm{g}}$, physical (nm) [26] & 110 & 110 & 100 & 100 & 90 & 90 \\
Tunnel oxide thickness (nm) [27] & $8-9$ & $8-9$ & $8-9$ & $8-9$ & 8 & 8 \\
Interpoly dielectric material [28] & ONO & ONO & ONO & ONO & High- $k$ & High- $k$ \\
Interpoly dielectric thickness EOT (nm) & $13-15$ & $13-15$ & $13-15$ & $13-15$ & $8-10$ & $8-10$ \\
Gate coupling ratio [29] & $0.6-0.7$ & $0.6-0.7$ & $0.6-0.7$ & $0.6-0.7$ & $0.6-0.7$ & $0.6-0.7$ \\
Highest W/E voltage (V) [30] & $7-9$ & $7-9$ & $7-9$ & $7-9$ & $6-8$ & $6-8$ \\
$I_{\text {read }}(\mu \mathrm{A}$ ) [31] & $21-27$ & $20-26$ & $19-25$ & $17-22$ & $15-20$ & $14-19$ \\
Endurance (erase/write cycles) [32] & $1.0 \times 10^{5}$ & $1.0 \times 10^{5}$ & $1.0 \times 10^{5}$ & $1.0 \times 10^{5}$ & $1.0 \times 10^{6}$ & $1.0 \times 10^{6}$ \\
Nonvolatile date retention (years) [33] & $10-20$ & $10-20$ & $10-20$ & $10-20$ & 20 & 20 \\
Maximum number of bits per cell (MLC) [34] & 2 & 2 & 2 & 2 & 2 & 2 \\
Array architecture (with cell contact (CC) or & CC & CC & CC & CC & CC/VG & CC/VG \\
virtual ground (VG)) [35] & & & & &
\end{tabular}


Table 2. ITRS Scaling projections for floating-gate NAND Flash [18].

\begin{tabular}{|c|c|c|c|c|c|c|}
\hline Year of production & 2009 & 2010 & 2011 & 2012 & 2013 & 2014 \\
\hline DRAM 1/2 pitch (nm) (contacted) & 50 & 45 & 40 & 35 & 32 & 28 \\
\hline MPU/ASIC metal I (MI) 1/2 PITCH (nm) contacted & 54 & 45 & 38 & 32 & 27 & 24 \\
\hline (ORTC) NAND flash poly $1 / 2$ pitch (nm) & 38 & 32 & 28 & 25 & 23 & 20 \\
\hline (PIDS) NAND flash poly $1 / 2$ pitch (nm) & 34 & 32 & 28 & 25 & 22 & 20 \\
\hline \multicolumn{7}{|l|}{ NAND flash } \\
\hline NAND flash technology node $-F(\mathrm{~nm})[1]$ & 34 & 32 & 28 & 25 & 22 & 20 \\
\hline Number of word lines in one NAND string [2] & 64 & 64 & 64 & 64 & 64 & 64 \\
\hline Cell type (FG, CT, 3D, etc.) [3] & FG & FG & FG & $\mathrm{FG} / \mathrm{CT}$ & $\mathrm{FG} / \mathrm{CT}$ & $\mathrm{CT} / 3 \mathrm{D}$ \\
\hline 3D NAND number of memory layers & 1 & 1 & 1 & 1 & 1 & 2 \\
\hline \multicolumn{7}{|l|}{ A. Floating gate NAND flash } \\
\hline Cell size-area factor in a multiples of $F^{2}$ SLC/MLC [4] & $4.0 / 1.3$ & $4.0 / 1.3$ & $4.0 / 1.3$ & $4.0 / 1.0$ & $4.0 / 1.0$ & $4.0 / 1.0$ \\
\hline Tunnel oxide thickness (nm) [5] & $6-7$ & $6-7$ & $6-7$ & $6-7$ & $6-7$ & $6-7$ \\
\hline Interpoly dielectric material [6] & ONO & ONO & ONO & High- $k$ & High- $k$ & High- $k$ \\
\hline Interpoly dielectric thickness (nm) & $10-13$ & $10-13$ & $10-13$ & $9-10$ & $9-10$ & $9-10$ \\
\hline Gate coupling ratio (GCR) [7] & $0.6-0.7$ & $0.6-0.7$ & $0.6-0.7$ & $0.6-0.7$ & $0.6-0.7$ & $0.6-0.7$ \\
\hline Control gate material [8] & $n$-Poly & $n$-Poly & $n$-Poly & Poly/metal & Poly/metal & Poly/metal \\
\hline Highest W/E voltage (V) [9] & $17-19$ & $17-19$ & $17-19$ & $15-17$ & $15-17$ & $15-17$ \\
\hline Endurance (erase/write cycles) [10] & $1.0 \times 10^{5}$ & $1.0 \times 10^{5}$ & $1.0 \times 10^{5}$ & $1.0 \times 10^{4}$ & $1.0 \times 10^{4}$ & $1.0 \times 10^{4}$ \\
\hline Nonvolatile date retention (years) [11] & $10-20$ & $10-20$ & $10-20$ & $10-20$ & $10-20$ & 20 \\
\hline Maximum number of bits per cell (MLC) [12] & 3 & 3 & 3 & 4 & 4 & 4 \\
\hline
\end{tabular}

\section{Background Knowledge}

The structure of a charge trapping memory transistor is similar to that of a regular metal oxide silicon (MOS) transistor, except for an additional dielectric layer (charge trapping layer) between the blocking layer and the tunneling layer. Figure 1 shows the cross-section schematic. The charge-trapping layer is electrically isolated from surrounding layers on all sides by dielectrics. The dielectric layer between the charge trapping layer and the gate is called the blocking layer or inter-poly dielectric (IPD) because both of the gate and IPD are usually made of poly-silicon originally. The dielectric closest to the substrate is called the tunnel layer. The name originates from the working principle that the erase operation and the program operation injects through this thin oxide via quantum mechanical tunneling.

As the name indicates, the charge-trapping layer serves as the charge storage dielectric. Charge-trapping type flash memory determines the digital " 1 " and " 0 " by charges insertion and removal from the charge-trapping layer, which can be considered as program/erase processes respectively. The program/erase speed is usually defined as variation of threshold voltage with respect to time. Figure 2 presents the program/erase speed of one kind of CTMs. For instance, concerning the program mode, a positive pulse is applied to the gate, causing electrons to be injected from the substrate into the charge-trapping layer. The stored electrons lead to a positive shift of threshold voltage. In the erase mode, a negative pulse is applied to the gate in order to cause holes to be injected from the substrate into the CTL, and/or electrons escaping from the CTL into the substrate, which causes a negative shift of threshold voltage. Obviously, a low operating voltage with a short pulse-width (prompt program/erase speed) is desirable for memory devices nowadays. A blocking layer is used in flash 
memories. The thickness heavily influences program/erase speed and the magnitude of read current for an industry-standard flash cell. Low defect density and long mean time to failure, together with charge retention capability, are important reliability issues.

Figure 1. Cross-section schematic of a charge trapping memory transistor.

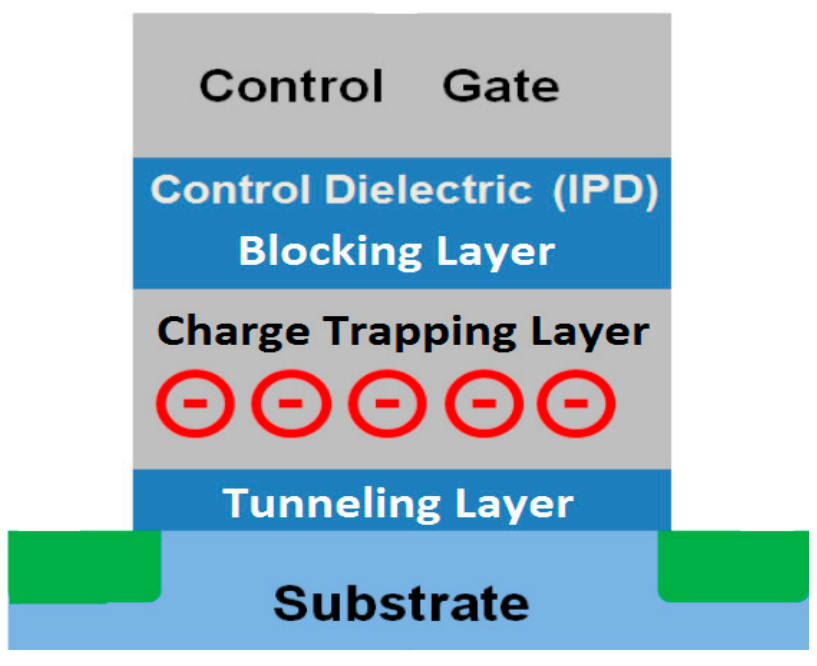

Figure 2. Program and erase characteristics of SANOS devices. Reused with permission from [34], Copyright 1997, IEEE.

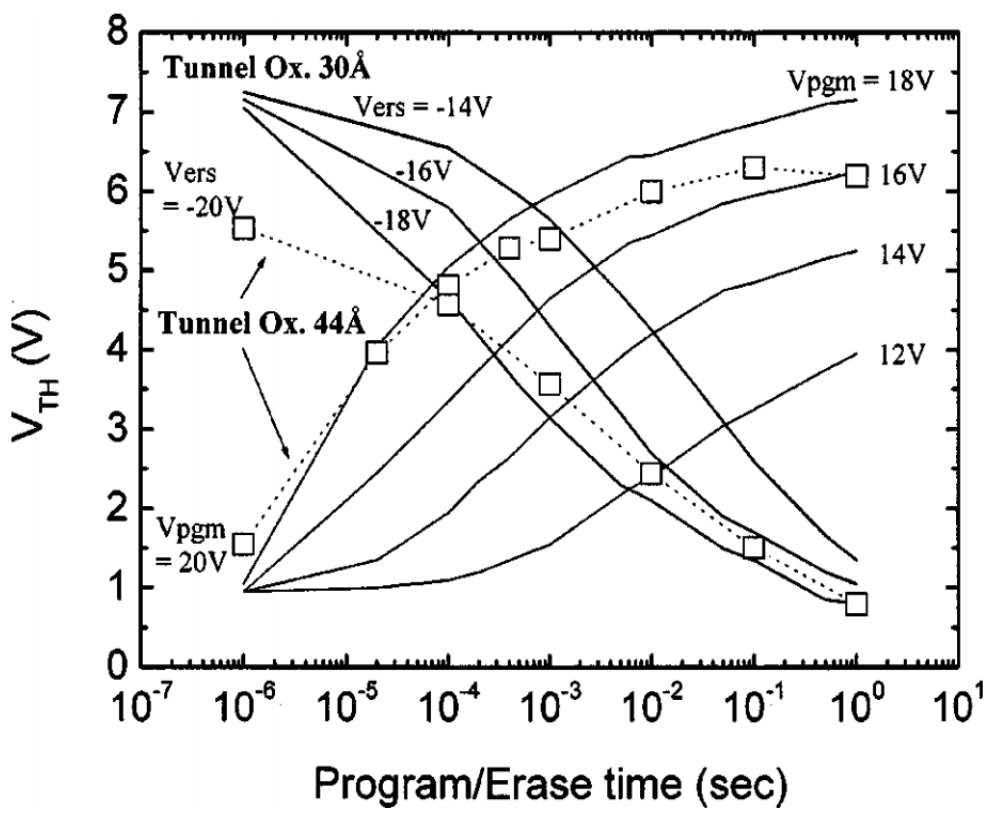

Programming is obtained by applying pulses to the control gate and to the drain simultaneously when the source is grounded. This operation can be performed selectively by applying the pulse to the word line (WL), which connects the control gates, and biasing the bit line (BL), which connects the drains [34]. The change in threshold voltage depends upon the width of the programming pulse. For some cases, to have a voltage shift of around 3, 3.5 V, a pulse width with typical values in the 1-10 us range must be applied. A rapid change in cell $V_{\mathrm{T}}$ occurs initially. Then, as the charge trapping layer potential drops below the drain potential, $V_{\mathrm{T}}$ saturates. At this point, we can define an intrinsic threshold. The electric field in the tunnel oxide close to the drain reverses and electron injection into 
the charge-trapping layer is much less favorable [35]. Intrinsic threshold voltage shift, roughly, does not depend on the channel length but depends on the coupling ratios (the overlap between the charge trapping layer and control gate on field oxide). In addition, intrinsic threshold voltage shift also depends linearly on drain voltage. Temperature also has an influence on programming speed. A higher temperature reduces the number of hot electrons available for injection, hence retarding the programming characteristics.

The erase operation requires a high voltage pulse to be applied to the source (common to all the transistors in the array/block) when control gates (WL) are grounded and drains (BL) floating. Before applying the erase pulse, all the cells in the array/block are programmed to start with all the thresholds approximately at the same value [34]. After that, an erase pulse having a controlled width is applied. Electrical erase is achieved via tunneling of charge from the charge-trapping layer to the source. To have a junction that can sustain the high, applied voltages without breaking down, the source junction needs to be carefully designed. A high electric field through the tunnel oxide means that even the electric field at the surface of the silicon is very high, and this can give rise to a leakage current due to band-to-band tunneling (BBT) or breakdown of the source/substrate junction. Source breakdown is one of the major limiting factors to erase time reduction, since the higher the voltage applied to the source, the shorter the erasing time. One of the solutions to the problem is achieved by optimizing the source junction profile to a more gradual one in order to reduce the electric field at the junction.

As for the endurance characteristic, the flash memory device is required to maintain its properties on being subjected to repeated program/erase cycles. Figure 3 demonstrates the endurance characteristic of a CTM, although the trend of threshold voltage variation seems not the same as others. When thin dielectrics are repeatedly stressed at high electric fields, oxide, interface, and bulk traps generate in the dielectric. Charge is trapped and released from these traps, and thus it changes the fields across the dielectric. This tends to modify the program/erase characteristics over time, as damage is induced in the dielectric. Flash memories are generally expected to last for $10^{5}$ cycles without distinct degradation.

Figure 3. Endurance characteristic of $35 \% \quad \mathrm{Al}-\mathrm{GdAlO}_{x}$ and $\mathrm{Al}_{2} \mathrm{O}_{3}$ blocking layers. Reused with permission from [35], Copyright 1992, IEEE.

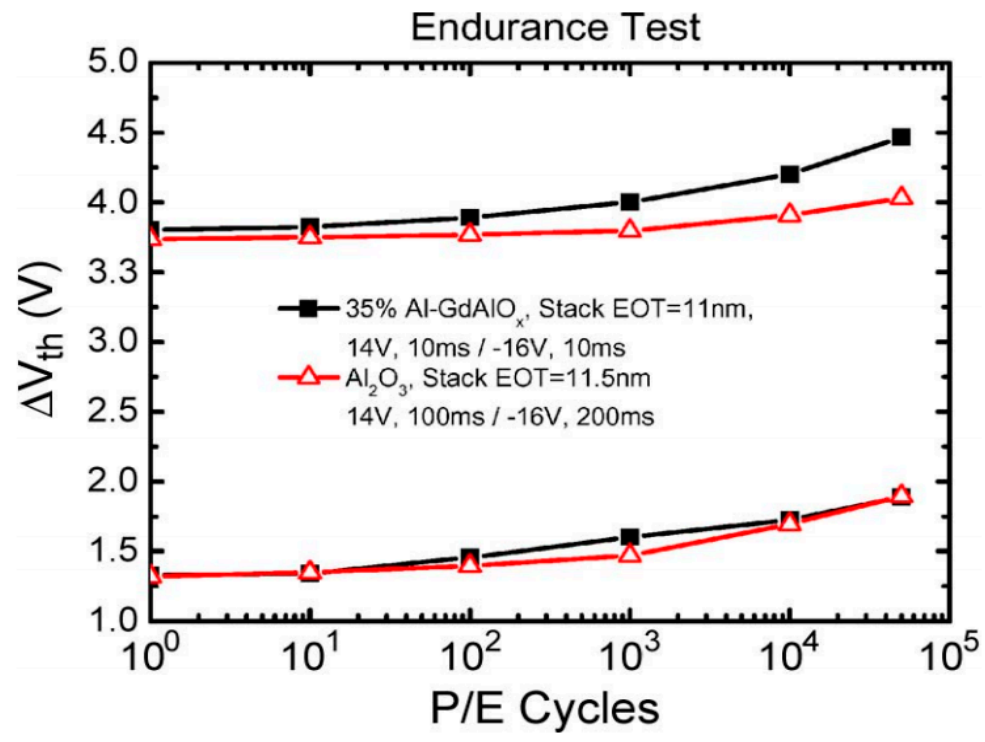


Cycling is known to cause a fairly uniform wear-out of the cell performance, mainly due to tunnel oxide degradation, which eventually limits the endurance characteristics [36]. As the experiment was performed applying constant pulses, the variations of program and erase threshold voltage levels are described as "program/erase threshold voltage window closure" and give a measure of the tunnel oxide aging. In particular, the reduction of the programmed threshold with cycling is due to trap generation in the oxide and to interface state generation at the drain side of the channel, which are mechanisms specific to hot-electron degradation. The evolution of the erase threshold voltage reflects the dynamics of net fixed charge in the tunnel oxide as a function of the injected charge. Cycling wear-out can be reduced by proper device engineering and by optimization of the tunnel oxide process. In fact, a high field stress on thin oxide is known to increase the current density at low electric field. The excess current component, which causes a significant deviation from the current-voltage (I-V) curves from the theoretical Fowler-Nordheim characteristics at low field, is known as stress-induced leakage current (SILC). SILC is clearly attributed to stress-induced oxide defects and, as far as a conduction mechanism, it is attributed to a trap assisted tunneling. The main parameters controlling SILC are the stress field, the amount of charge injected during the stress, and the oxide thickness.

The retention characteristic is significant in non-volatile memory devices. The ability to retain charge without supplied power is the definition of non-volatile memory. Retention is a metric used to quantify the extent of time expected for which the stored charge is kept in the flash memory. Figure 4 shows an example of retention characteristics of a certain CTM. The charge-loss in the retention mode is determined by tunneling leakage under weak fields through adjacent dielectrics. This charge-loss would be greatly amplified if the dielectrics contained defects or traps, since it would enhance trap-assisted tunneling. A typical retention benchmark for flash memories is calculated for 10 years. Retention tests are further accelerated under higher temperatures. For instance, a $24 \mathrm{~h}$ retention measurement at $85^{\circ} \mathrm{C}$ is utilized. In updated Flash technology, due to the small cell size, the capacitance is very small and at an operative programmed threshold shift corresponds a number of electrons in the order of $10^{3}$ to $10^{4}$. A loss of $20 \%$ in this number (around 2-20 electrons lost per month) can lead to a wrong read of the cell and then to a data loss.

Possible causes of charge loss are [36]: (1) defects in the tunnel oxide; (2) defects in the blocking dielectric; (3) mobile ion contamination; and (4) detrapping of charge from insulating layers surrounding the CTL. The generation of defects in the tunnel oxide can be divided into an extrinsic and an intrinsic one. The former is due to defects in the device structure; the latter to the physical mechanisms that are used to program and erase the cell. The best blocking dielectric considering both intrinsic properties and process integration issues has been demonstrated to be a triple layer. The problem of mobile ion contamination has been already solved, taking particular care with the process control, but in particular using high phosphorus content in intermediate dielectric as a guttering element. Electrons can be trapped in the insulating layers surrounding the floating gate during wafer processing, as a result of the so-called plasma damage, or even during the ultra-violet (UV) exposure normally used to bring the cell in a well-defined state at the end of the process. This apparent charge loss disappears if the process ends with a thermal treatment able to remove the trapped charge. Finally, the retention capability of Flash memories has to be checked by using accelerated tests that usually adopt screening electric fields and hostile environments at high temperature. 
Figure 4. Retention characteristics at $85{ }^{\circ} \mathrm{C}$ represented by normalized retained charge for the programmed state of the memory with as-deposited and annealed $\mathrm{ZrON}$ films. Reused with permission from [37], Copyright 2010, IEEE.

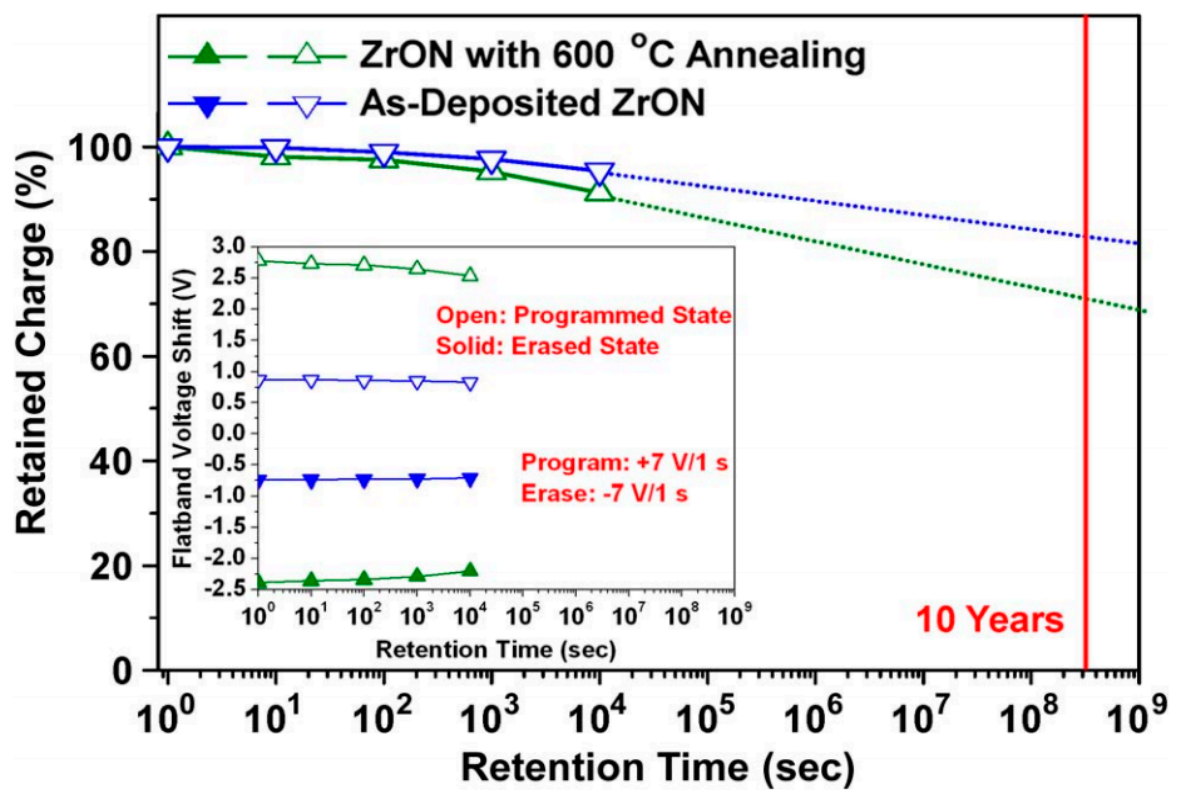

\section{Recent Developments}

\subsection{Charge Trapping Layer}

Advancements in ultra-thin tunnel oxides during the 1990s have opened the path to improved performance and reliability for non-volatile memory (NVM) based on silicon-oxide-nitride-silicon (SONOS) technology. The storage region for the floating-gate structure is the conducting polysilicon floating-gate electrode, while the SONOS uses a thin silicon-nitride film $\left(\mathrm{Si}_{3} \mathrm{~N}_{4}\right)$ [38]. An advantage of the SONOS device over the floating-gate device is its improved endurance, since a single defect will not cause the discharge of the memory. The stored charge in the SONOS memory device lies in isolated sites within the silicon nitride dielectric. While for the floating-gate device, the case is totally different. A single defect can discharge the stored memory charge of the device due to the conductive properties of the floating polysilicon gate electrode. In the late 1980s and early 1990s, n- and p-channel SONOS devices emerged with write/erase voltages of 5-12 V. Low-voltage SONOS NVMs may be scaled in cell size to $6 F^{2}(F=$ feature size $)$ and perhaps even smaller.

Continuous down-scaling of SONOS devices is required by scaling down the charge-trapping layer to $<6 \mathrm{~nm}$, to suppress short-channel effects. This is challenging since the charge trapping deteriorates when the $\mathrm{Si}_{3} \mathrm{~N}_{4}$ is made thinner. Very little charge trapping was shown for a $2 \mathrm{~nm} \mathrm{Si}_{3} \mathrm{~N}_{4}$ layer used as the tunnel layer of SONOS. The high temperature retention also gets worse when the $\mathrm{Si}_{3} \mathrm{~N}_{4}$ is thin, due to the higher trap energy in the oxide $/ \mathrm{Si}_{3} \mathrm{~N}_{4} /$ oxide, arising from quantum confinement. A novel charge-trap-engineered flash NVM device was proposed in 2008 [39]. This combines a $5 \mathrm{~nm} \mathrm{Si}_{3} \mathrm{~N}_{4}$ with a $0.9 \mathrm{~nm}$ equivalent oxide thickness (EOT) layer of HfON, within double-barrier and double-tunnel layers, and still shows good retention and a large memory window (schematic energy band diagram of the structure shown in Figure 5). At $150{ }^{\circ} \mathrm{C}$ and $\pm 16 \mathrm{~V}$ program/erase $(\mathrm{P} / \mathrm{E})$, the device showed a $\mathrm{P} / \mathrm{E}$ 
speed of $100 \mu \mathrm{s}$, an initial $\Delta V_{\text {th }}$ window of $5.6 \mathrm{~V}$ and extrapolated 10 year retention of $3.8 \mathrm{~V}$. These results are much better than those of a control charge trap flash device with a single $\mathrm{Si}_{3} \mathrm{~N}_{4}$ trapping layer, which had a smaller initial $\Delta V_{\text {th }}$ and poorer 10-year retention.

$\mathrm{Si}_{3} \mathrm{~N}_{4}$ has a low dielectric constant $(k \sim 7)$, which limits the continual down-scaling of cell size and reduction of operating voltage. To solve these issues, various high- $k$ dielectrics with higher $k$ value have been widely investigated as charge trapping layer. Other than having a larger conduction-band offset with respect to the tunnel dielectric and, thus, better charge retention, a high- $k$ dielectric should also allow a higher electric field over the tunnel dielectric and results in enhanced P/E speed. Most of high- $k$ dielectric used in the charge-trapping layer are amorphous phase. However, crystalline high- $k$ dielectrics, such as tetragonal and cubic $\mathrm{ZrO}_{2}$, have theoretical $k$-values of 46.6 and 36.8, respectively, which are much higher than their amorphous-phase counterpart and will be beneficial to enhance memory performance. A cubic $\mathrm{ZrO}_{2}$ film formed by annealing of amorphous $\mathrm{ZrON}$ has been investigated as the charge-trapping layer for nonvolatile memory [37]. The memory with a nitrogen-stabilized cubic $\mathrm{ZrO}_{2}$ film shows promising performance in terms of $3.81 \mathrm{~V}$ hysteresis memory window by $\pm 7 \mathrm{~V} \mathrm{P} / \mathrm{E}$ voltage and $1.98 \mathrm{~V}$ flat-band voltage shift by programming at $+7 \mathrm{~V}$ for $10 \mathrm{~ms}(\mathrm{P} / \mathrm{E}$ transient characteristic shown in Figure 6). Improved performance is mainly due to the greatly enhanced $k$-value of 32.8 and the increased trapping sites provided by grain boundaries.

Figure 5. Schematic energy band diagram of double-barrier, double-tunnel and charge-trapping-engineered flash memory. Reused with permission from [39], Copyright 2008, IEDM.

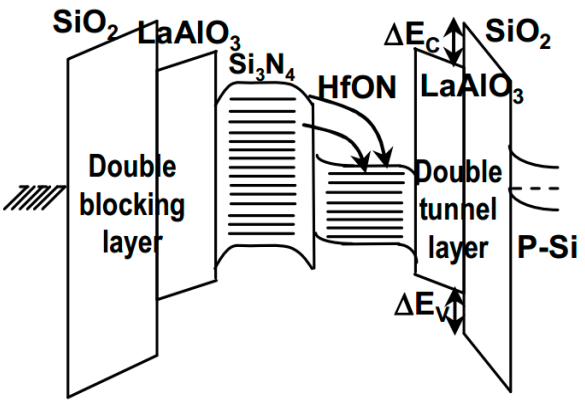

Figure 6. Comparison of $\mathrm{P} / \mathrm{E}$ transient characteristics for the memory with as-deposited and annealed ZrON films. Reused with permission from [37], Copyright 2010, IEEE.

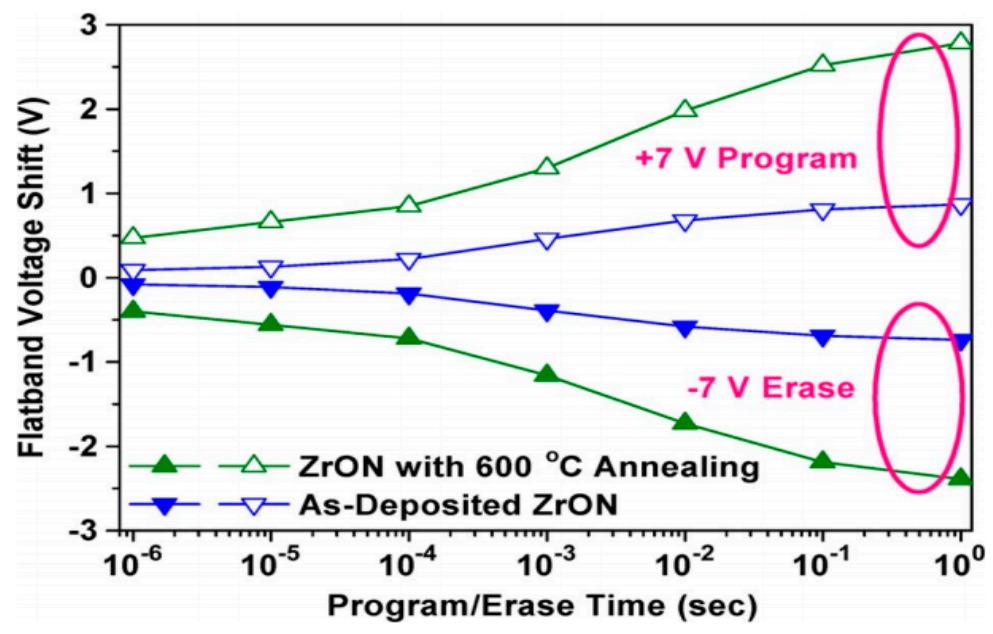


The charge trapping and tunneling characteristics of $\mathrm{HfO}_{2}$ layer that replaces $\mathrm{Si}_{3} \mathrm{~N}_{4}$ layer as trap layer were investigated by You et al. [40]. The metal-hafnium-oxide-semiconductor (MHOS) structure capacitors with various thicknesses of $\mathrm{HfO}_{2}$ layer were fabricated in 2010. The electrical properties of MHOS structure capacitors were compared with those of metal-nitride-oxide-semiconductor (MNOS) structure capacitors. The gate leakage current of MHOS capacitor due to tunneling was significantly reduced by stacking the $\mathrm{HfO}_{2}$ trap layer on thin $\mathrm{SiO}_{2}$ tunnel layer. The MHOS capacitors showed a larger memory window than the MNOS capacitors at the same trap layer thickness, because the $\mathrm{HfO}_{2}$ layer has better charge trapping efficiency than the $\mathrm{Si}_{3} \mathrm{~N}_{4}$ layer. Especially, the $\mathrm{Si}_{3} \mathrm{~N}_{4}$ trap layer is difficult to reduce the film thickness below $4 \mathrm{~nm}$ thick due to enormous increase of the tunneling current. However, the $\mathrm{HfO}_{2}$ trap layer can reduce the thickness below $4 \mathrm{~nm}$. It is also observed that the ultrathin $\mathrm{HfO}_{2}$ trap layer with a thickness of $2 \mathrm{~nm}$ stored almost the same charges with $\mathrm{Si}_{3} \mathrm{~N}_{4}$ layer with a thickness of $7 \mathrm{~nm}$. Even in ultrathin trap layer with a thickness of $2 \mathrm{~nm}$, the memory window of $\mathrm{HfO}_{2}$ layer $(0.67 \mathrm{~V})$ is much higher than that of the $\mathrm{Si}_{3} \mathrm{~N}_{4}$ layer $(0.025 \mathrm{~V})$ and shows a similar value to $7 \mathrm{~nm}$ thick $\mathrm{Si}_{3} \mathrm{~N}_{4}$ trap layer.

Yang et al. [41] have studied the nitrogen composition dependence of the characteristics of $\mathrm{TaN} / \mathrm{HfLaON} / \mathrm{Hf}_{1-x-y} \mathrm{~N}_{x} \mathrm{O}_{y} / \mathrm{SiO}_{2} / \mathrm{Si}$ (MONOS) memory devices in 2008. To overcome performance degradation of increased $\mathrm{P} / \mathrm{E}$ voltage and write speed, the use of an $\mathrm{Al}(\mathrm{Ga}) \mathrm{N}$ storage layer was proposed which has deeper $\Delta E_{\mathrm{C}}$ than $\mathrm{Si}_{3} \mathrm{~N}_{4}$. This improved the $\mathrm{P} / \mathrm{E}$ voltage and write speeds in such deep-trap MONOS devices. Unfortunately, further improvement beyond $\mathrm{Al}(\mathrm{Ga}) \mathrm{N}$ is limited since most of the metal-nitrides are metallic. To avert this problem, a higher $k \mathrm{Hf}_{1-x-y} \mathrm{~N}_{x} \mathrm{O}_{y}$ dielectric was used for MONOS applications, where even lower P/E voltages and better high temperature retention can be achieved. Here, the nitride composition in the $\mathrm{Hf}_{1-x-y} \mathrm{~N}_{x} \mathrm{O}_{y}$ beyond was varied to investigate how this alters the characteristics. Transistor device structure is shown in Figure 7. Increasing the $\mathrm{N}$ composition in the $\mathrm{Hf}_{1-x-y} \mathrm{~N}_{x} \mathrm{O}_{y}$ trapping layer has improved both the memory window and high-temperature retention. The $\mathrm{Hf}_{0.3} \mathrm{~N}_{0.2} \mathrm{O}_{0.5}$ MONOS device showed $\pm 9 \mathrm{~V} \mathrm{P} / \mathrm{E}$ voltage, $100 \mu \mathrm{s} \mathrm{P} / \mathrm{E}$ speed, large initial $2.8 \mathrm{~V}$ memory window, and a ten-year expected retention of $1.8 \mathrm{~V}$ at $85{ }^{\circ} \mathrm{C}$ or $1.5 \mathrm{~V}$ at $125{ }^{\circ} \mathrm{C}$. Good endurance was obtained, as is evident from the still memory windows of 2.4 and $1.7 \mathrm{~V}$ after $10^{5}$ cycles at $\pm 9 \mathrm{~V} 100 \mu \mathrm{s} / \mathrm{E}$ for $\mathrm{Hf}_{0.3} \mathrm{~N}_{0.2} \mathrm{O}_{0.5}$ and $\mathrm{Hf}_{0.35} \mathrm{~N}_{0.10} \mathrm{O}_{0.55}$ MONOS devices.

Figure 7. TaN/HfLaON/Hf $\mathrm{H}_{0.35} \mathrm{~N}_{0.10} \mathrm{O}_{0.55} / \mathrm{SiO}_{2} / \mathrm{Si}$ MONOS transistors device structure. Reused with permission from [41], Copyright 2008, IEEE.

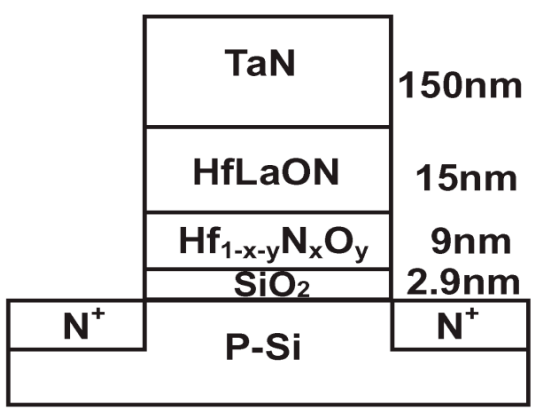

The polysilicon-oxide-high- $k$-oxide-silicon (SOHOS) structure, with hafnium oxide $\left(\mathrm{HfO}_{2}\right)$ as the charge-storage layer, demonstrates a superior charge-storage capability at low voltages, faster programming, and less over-erase problems compared to the conventional SONOS devices. However, 
the SOHOS device has a poorer charge-retention capability than the SONOS one. While using aluminum oxide $\left(\mathrm{Al}_{2} \mathrm{O}_{3}\right)$ as the charge-storage layer results in a SOHOS structure with an improved charge-retention performance, but at the expense of a slower programming speed. Therefore, by adding a small amount of aluminum to $\mathrm{HfO}_{2}$ to form hafnium aluminum oxide (HfAlO), the SOHOS structure with $\mathrm{HfAlO}$ as the charge-storage layer can combine the advantages of both $\mathrm{HfO}_{2}$ and $\mathrm{Al}_{2} \mathrm{O}_{3}$, like fast programming speed and good charge-retention capability [42]. From the programming $\left(V_{\mathrm{g}}-V_{\mathrm{fb}}=6 \mathrm{~V}\right)$ and erasing $\left(V_{\mathrm{g}}-V_{\mathrm{fb}}=-6 \mathrm{~V}\right)$ characteristics, respectively, HfAlO as charge-trapping layer devices show the fastest programming and erase speed while the $\mathrm{Al}_{2} \mathrm{O}_{3}$ device is the slowest. The memory window is $3 \mathrm{~V}$ at $100 \mathrm{~ms}$ of $\mathrm{P} / \mathrm{E}$ process. The write/erase (W/E) endurance characteristic of the HfAlO device shows no discernible difference from that of the $\mathrm{Si}_{3} \mathrm{~N}_{4}$ device. Both $\mathrm{Si}_{3} \mathrm{~N}_{4}$ and $\mathrm{HfAlO}$ devices show a negligible degradation in the threshold voltage window after $10^{4} \mathrm{~W} / \mathrm{E}$ cycles. The dominant charge-storage mechanism is due to electron trapping in the bulk of the HfAlO layer, rather than negative charge trapping at the tunnel oxide/high- $k$ interface, which will be independent of the HfAlO thickness. The charge-retention performance of the SOHOS device also degrades with the decreasing HfAlO thickness. This can be understood from the fact that, for SOHOS devices with a thicker HfAlO layer, electrons that are trapped within the bulk may have to tunnel through a longer distance through the HfAlO layer to the tunnel $\mathrm{SiO}_{2}$ and the silicon substrate. The initial $V_{\mathrm{fb}}$ after programming is $3.5 \mathrm{~V}$ for $12.5 \mathrm{~nm} \mathrm{HfAlO}$ and after $10^{4} \mathrm{~s}$ the value retains at $3.4 \mathrm{~V}$.

The rare earth oxides such as yttrium oxide $\left(\mathrm{Y}_{2} \mathrm{O}_{3}\right)$ are attractive candidates for the trapping layer memory based on thermodynamic stability consideration, a high dielectric constant of 18 , a high conduction band offset over $2 \mathrm{eV}$, and a low lattice mismatch with silicon. Pan et al., proposed a novel high- $k \mathrm{Y}_{2} \mathrm{O}_{3}$ SONOS-type flash memory in 2008 [43]. Schematic representation of flash memory cell structure is shown in Figure 8. These high- $k \mathrm{Y}_{2} \mathrm{O}_{3}$ SONOS-type memories exhibited large threshold voltage shifting, almost negligible read and gate disturb, excellent data retention (charge loss of $\sim 4 \%$ measured time up to $10^{4} \mathrm{~s}$ and at room temperature, expected $\sim 22 \%$ charge loss for ten years at $125{ }^{\circ} \mathrm{C}$ ), and superior endurance characteristics (program/erase cycles up to $10^{5}$ ) because of the higher probability for trapping charge carriers. For the condition of $V_{\mathrm{D}}=6 \mathrm{~V}$ and $V_{\mathrm{G}}=8 \mathrm{~V}$ at $1 \mathrm{~ms}$, it is obvious that a high- $\mathrm{K}_{2} \mathrm{O}_{3}$ SONOS-type memory after $\mathrm{N}_{2}$ annealing exhibits a larger memory window of $2.43 \mathrm{~V}$ compared with other annealing gases. This is due to more electrons trapped in the $\mathrm{Y}_{2} \mathrm{O}_{3}$ layer. Moreover, excellent erase speed of approximately $1 \mathrm{~ms}$ can be obtained for Y-silicate trapping storage layer memory prepared at a $\mathrm{N}_{2}$ ambient annealing and operated at $V_{\mathrm{D}}=8 \mathrm{~V}$ and $V_{\mathrm{G}}=-3 \mathrm{~V}$. The values of $V_{\text {th }}$ in the program and erase states for $\mathrm{Y}$-silicate charge trapping layer memory prepared at a $\mathrm{N}_{2}$ gas annealing did not increase significantly up to $10^{5} \mathrm{P} / \mathrm{E}$ cycles. The trapped electrons from the Y-silicate layer are almost removed during the erase process. In contrast, the memory window underwent a narrowing after $10^{5}$ cyclic operations for high- $k \mathrm{Y}_{2} \mathrm{O}_{3}$ SONOS-type memory after $\mathrm{O}_{2}$ annealing. An yttrium silicate trapping storage layer memory annealed in $\mathrm{N}_{2}$ gas exhibits a small charge loss of about $4 \%$ measured time up to $10^{4} \mathrm{~s}$ and at $25^{\circ} \mathrm{C}$. This result is attributed to the combined effects of the tight embrace of the $\mathrm{Y}_{2} \mathrm{O}_{3}$ film by the sufficiently deep trap energy level. Although the thickness of tunnel oxide is $2 \mathrm{~nm}$, almost no significant lateral or vertical charge migration occurs. At the temperature of $125{ }^{\circ} \mathrm{C}$, SONOS-type memory prepared under an $\mathrm{Y}_{2} \mathrm{O}_{3}$ trapping layer and annealed in $\mathrm{N}_{2}$ gas has a lower charge loss of $22 \%$ during the program state compared with other annealing gases. This indicates that the yttrium silicate charge-trapping layer can 
tightly catch the tunneling electrons. Therefore, the trapped electrons by the high- $k \mathrm{Y}_{2} \mathrm{O}_{3}$ SONOS-type memory devices cannot easily escape, and the exhibited charge loss percentage is low.

One difficulty in SONOS is the small conduction band discontinuity at the $\mathrm{Si}_{3} \mathrm{~N}_{4} / \mathrm{SiO}_{2}$ interface, which causes the charge leak out from the shallow trap levels of $\mathrm{Si}_{3} \mathrm{~N}_{4}$. To overcome this problem, high- $k$ dielectric materials, such as $\mathrm{ZrO}_{2}, \mathrm{HfO}_{2}$, and $\mathrm{Y}_{2} \mathrm{O}_{3}$ are promising candidates to replace a $\mathrm{Si}_{3} \mathrm{~N}_{4}$ film as the charge trapping layer of SONOS Flash devices. Such high- $k$ dielectric films can achieve improved charge trapping characteristics than the $\mathrm{Si}_{3} \mathrm{~N}_{4}$ films because of their sufficient densities of trap states and deep trap energy levels, giving rise to better data retention. In recent years, rare-earth oxides have attracted much interest in research for complementary metal oxide semiconductor applications of high- $k$ materials due to their large energy band gaps and high dielectric constants. Among them, $\mathrm{Tb}_{2} \mathrm{O}_{3}$ possesses desirable properties for charge trap Flash device application, such as a relatively high dielectric constant, a large band gap, a large conduction band offset with regard to silicon and good thermal stability with $\mathrm{Si}$. A metal-oxide-high-k-oxide-silicon (MOHOS)-type memory structure fabricating a high- $k \mathrm{~Tb}_{2} \mathrm{O}_{3}$ charge-trapping layer for flash memory applications was reported afterwards [44]. The high- $k \mathrm{~Tb}_{2} \mathrm{O}_{3}$ MOHOS-type memories annealed at $800{ }^{\circ} \mathrm{C}$ exhibited large threshold voltage shifting (memory window of $1.41 \mathrm{~V}$ operated at $V_{\mathrm{g}}=8 \mathrm{~V}$ at $0.1 \mathrm{~s}$ ), excellent data retention (charge loss of $10 \%$ measured time up to $10^{4} \mathrm{~s}$ and at $85{ }^{\circ} \mathrm{C}$ ), and good endurance characteristics (program/erase cycles up to $10^{5}$ ) because of the high probability and deep trap level for trapping the charge carrier due to the formation of the crystallized $\mathrm{Tb}_{2} \mathrm{O}_{3}$ with a high dielectric constant of 11.8 .

Figure 8. Schematic representation of flash memory cell structure using the $\mathrm{Y}_{2} \mathrm{O}_{3}$ as a charge-trapping layer. Reused with permission from [43], Copyright 2008, IEEE.

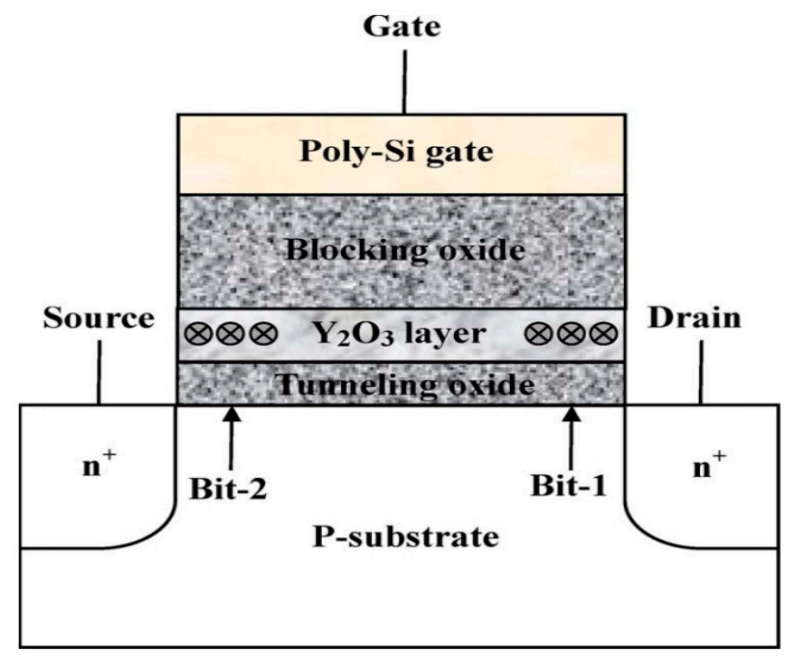

Several efforts have been made to improve both the retention time and the programming speed in SONOS devices. However, few of these solutions deal with the bottom tunneling oxide layer, which has already been scaled down to below $2 \mathrm{~nm}$. Further scaling tunneling oxide thickness and at the same time meeting the ten-year retention is a challenge even with these approaches. A novel memory structure, based on the band engineering considerations of $\mathrm{HfO}_{2}$ for the tunneling and blocking layer as well as $\mathrm{Ta}_{2} \mathrm{O}_{5}$ for the charge storage layer, was proposed to address these problems in 2004 [45]. Wang et al., demonstrate for the first time that $\mathrm{HfO}_{2}$ with its low charge barrier height and $\mathrm{Ta}_{2} \mathrm{O}_{5}$ with its 
deep-trap energy level and proper band offset alignments, are good candidates to replace the traditional $\mathrm{SiO}_{2}-\mathrm{Si}_{3} \mathrm{~N}_{4}-\mathrm{SiO}_{2}$ (ONO) stack to achieve faster programming and better retention performance simultaneously. The transistor structure is shown in Figure 9. The fabricated devices can be programmed as fast as $1 \mathrm{~ns}$ and erased from $10 \mathrm{~ns}$ at an $8 \mathrm{~V}$ gate bias. The retention decay rate of this device is improved by a factor more than three as compared to the conventional SONOS type devices.

The nanocrystals embedded dielectric structure has been proposed to replace the poly-Si floating-gate structure. Conventional high- $k$ materials, such as $\mathrm{ZrO}_{2}$ and $\mathrm{HfO}_{2}$, have low crystallization temperatures, e.g., lower than $600{ }^{\circ} \mathrm{C}$, which is a reliability concern. Various nanocrystalline semiconductive and conductive materials, such as $\mathrm{Ru}, \mathrm{RuO}$, indium tin oxide, and $\mathrm{ZnO}$, have been embedded into high- $k$ films as the electron-or hole-trapping media. Since molybdenum oxide $\left(\mathrm{MoO}_{x}\right)$ has a high work function, it can be a good charge trapping medium in the high- $k$ film: $\mathrm{ZrHfO}$ [46]. The nc- $\mathrm{MoO}_{x}$ sample shows a large $V_{\mathrm{FB}}$ shift of $0.52 \mathrm{~V}$ after the $8 \mathrm{~V}$ stress, which corresponds to the hole trapping density of $1.14 \times 10^{12} \mathrm{~cm}^{-2}$. On the other hand, for the same sample, a very small positive $V_{\mathrm{FB}}$ shift, i.e., $0.04 \mathrm{~V}$ is observed after the $+8 \mathrm{~V}$ stress. About $54 \%$ of trapped holes (under the $8 \mathrm{~V}$ stress condition) remain in the sample after 10 years. In addition, about $52 \%$ of trapped holes (under the $7 \mathrm{~V}$ stress condition) remain in the sample after 10 years.

Figure 9. Fabricated metal- $\mathrm{HfO}_{2}-\mathrm{Ta}_{2} \mathrm{O}_{5}-\mathrm{HfO}_{2}-\mathrm{Si}$ nMOS transistor structure. Reused with permission from [45], Copyright 2004, IEEE.

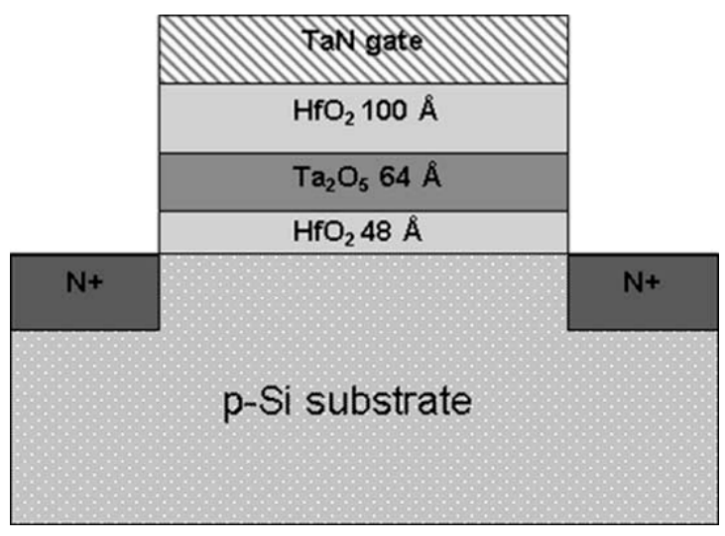

Extensive researches have been performed to study high- $k$ dielectrics instead of $\mathrm{Si}_{3} \mathrm{~N}_{4}$ as CTL for further scaling down of the memory dimensions and improving its charge-trapping efficiency, e.g., $\mathrm{Y}_{2} \mathrm{O}_{3}(k \sim 18)$, HfON $(k \sim 22), \mathrm{Pr}_{2} \mathrm{O}_{3}(k \sim 15), \mathrm{Nd}_{2} \mathrm{O}_{3}(k \sim 16), \mathrm{Er}_{2} \mathrm{O}_{3}(k \sim 13), \mathrm{ZrO}_{2}(k \sim 37)$, and $\mathrm{Ta}_{2} \mathrm{O}_{5}(k \sim 22)$. Unfortunately, few dielectrics proposed as CTL show a dielectric constant beyond 30. Among various high- $k$ dielectrics, $\mathrm{SrTiO}_{3}$ is well-known for its high dielectric constant $(k \sim 140)$ and zero band-offset with respect to silicon, both of which are desirable as CTL for memories to improve the program/erase $(\mathrm{P} / \mathrm{E})$ speeds and retention property. Nitrogen incorporation also plays an important role in the characteristics of $\mathrm{SrTiO}_{3}$ because it may induce more traps in the band gap through substitution of oxygen by nitrogen. Nitrided $\mathrm{SrTiO}_{3}$ [47] showed a larger memory window (8.4 $\mathrm{V}$ at $\pm 10 \mathrm{~V}$ sweeping voltage), higher $\mathrm{P} / \mathrm{E}$ speeds $(1.8 \mathrm{~V}$ at $1 \mathrm{~ms}+8 \mathrm{~V})$ and better retention properties (charge loss of $38 \%$ after $10^{4} \mathrm{~s}$ ), due to the nitrided $\mathrm{SrTiO}_{3}$ thin film exhibiting higher dielectric constant, higher deep-level traps induced by nitrogen incorporation, and suppressed formation of $\mathrm{Ti}$ silicate between the CTL and $\mathrm{SiO}_{2}$ by nitrogen passivation. 
$\mathrm{BaTiO}_{3}$ is well known for a high dielectric constant $(k>100)$ with strong scaling ability and its negative band offset with respect to $\mathrm{Si}$, thus, leading to a large barrier height relative to $\mathrm{SiO}_{2}$. In addition, $\mathrm{Zr}$-doped $\mathrm{BaTiO}_{3}$ has also attracted increasing interest because the isovalent substitution of Ti with $\mathrm{Zr}$ in $\mathrm{BaTiO} 3$ can shift the Curie temperature below room temperature, thus, making the dielectric paraelectric at room temperature without fatigue problems [48]. Also, $\mathrm{Zr}$-doped $\mathrm{BaTiO}_{3}$ has been demonstrated to have a lower leakage current than $\mathrm{BaTiO}_{3}$ while maintaining a comparable dielectric constant. Compared with the device without $\mathrm{Zr}$ incorporation, the one with $\mathrm{Zr}$ incorporation showed a similar memory window $(8.3 \mathrm{~V}$ at $\pm 12 \mathrm{~V}$ for $1 \mathrm{~s})$, but higher program speed at low gate voltage $(3.2 \mathrm{~V}$ at $100 \mu \mathrm{s}+6 \mathrm{~V})$ and better endurance and data retention (charge loss of $6.4 \%$ at $150{ }^{\circ} \mathrm{C}$ for $10^{4} \mathrm{~s}$ ), due to the $\mathrm{Zr}$-doped $\mathrm{BaTiO}_{3}$ exhibiting higher charge-trapping efficiency and higher density of traps. Under a $\pm 12 \mathrm{~V} 100 \mu$ s stress pulse the P/E windows of the Zr-BTO sample before and after the $10^{5}$-cycle stressing are 6.4 and $6.6 \mathrm{~V}$, respectively, and negligible degradation happens.

Using the high- $k$ dielectric as a trap layer has advantages of decreased program/erase voltage and improved retention characteristics as compared to the SONOS devices. These advantages can lead to the superior charge trap characteristics. However, the ONO structure must have over three steps to make three layers (bottom $\mathrm{SiO}_{2}$-thermal oxidation, $\mathrm{Si}_{3} \mathrm{~N}_{4}$-LPCVD, and top $\mathrm{SiO}_{2}-\mathrm{PECVD}$ ). On the other hand, multi-stacked films using the high- $k$ materials are generally able to make a one-step approach due to the oxide base. This means that a three-gas line (two sources line + one oxygen line) can make three layers. In order to investigate charge trap characteristics with various thicknesses of blocking and tunnel oxides for application to nonvolatile memory devices, Kim et al., fabricated two multi-stack films, respectively [49]. One is $\mathrm{Al}_{2} \mathrm{O}_{3}(5$ and $15 \mathrm{~nm}) / \mathrm{La}_{2} \mathrm{O}_{3}(5 \mathrm{~nm}) / \mathrm{Al}_{2} \mathrm{O}_{3}(5 \mathrm{~nm})$. The other is $\mathrm{Al}_{2} \mathrm{O}_{3}(15 \mathrm{~nm}) / \mathrm{La}_{2} \mathrm{O}_{3}(5 \mathrm{~nm}) / \mathrm{Al}_{2} \mathrm{O}_{3}(5,7.5$ and $10 \mathrm{~nm})$. The optimized structure was $15 \mathrm{~nm} \mathrm{Al}_{2} \mathrm{O}_{3}$ blocking oxide $/ 5 \mathrm{~nm} \mathrm{La} \mathrm{O}_{3}$ trap layer $/ 5 \mathrm{~nm} \mathrm{Al} \mathrm{O}_{3}$ tunnel oxide films. The maximum memory window of this film of about $1.12 \mathrm{~V}$ was observed at $11 \mathrm{~V}$ for $10 \mathrm{~ms}$ in the program mode and at $13 \mathrm{~V}$ for $100 \mathrm{~ms}$ in the erase mode (the $\mathrm{C}-\mathrm{V}$ hysteresis as a function of double-sweep voltage shown in Figure 10). The operation conditions of the P/E cycles were $11 \mathrm{~V}$ for $10 \mathrm{~ms}$ in the program mode and $13 \mathrm{~V}$ for $100 \mathrm{~ms}$ in the erase mode. The difference of the threshold voltages between the program and erase mode was about $1.2 \mathrm{~V}$ and was maintained over $10^{4} \mathrm{P} / \mathrm{E}$ cycles.

The programming characteristics of CTM devices can be enhanced by the high- $k$ CT layer due to its larger trap density and smaller band offset to Si. However, the retention characteristic is still an issue because high- $k$ material suffers lower crystalline temperature and shallower defect level. Therefore, a $\mathrm{Si}_{3} \mathrm{~N}_{4} /$ high- $k$ material stacked CT layer was proposed to improve the retention characteristics since $\mathrm{Si}_{3} \mathrm{~N}_{4}$ has deeper trap level and higher crystalline temperature and provides an effective barrier for high- $k$ material such as $\mathrm{HfO}_{2}$. Moreover, a faster erase speed can also be achieved by its smaller valence band offset for $\mathrm{Si}_{3} \mathrm{~N}_{4}$ to $\mathrm{Si}$. Multilevel cell characteristics can be obtained by inserting $\mathrm{Al}_{2} \mathrm{O}_{3}$ into $\mathrm{Si}_{3} \mathrm{~N}_{4}$ (i.e., $\mathrm{Si}_{3} \mathrm{~N}_{4} / \mathrm{Al}_{2} \mathrm{O}_{3} / \mathrm{Si}_{3} \mathrm{~N}_{4}$ trapping layer) due to the modulated trapping charge distribution. CT NVM devices with $\mathrm{Si}_{3} \mathrm{~N}_{4} / \mathrm{Al}_{2} \mathrm{O}_{3} /$ high- $k$ CT layer is then proposed to further scale down [50]. The sample with $\mathrm{Si}_{3} \mathrm{~N}_{4} / \mathrm{Al}_{2} \mathrm{O}_{3} / \mathrm{HfO}_{2} \mathrm{CT}$ layer has the fastest programming speed since it can modulate the trapped charge distribution. By inserting an $\mathrm{Al}_{2} \mathrm{O}_{3}$ layer between $\mathrm{Si}_{3} \mathrm{~N}_{4}$ and $\mathrm{HfO}_{2}$, most of the injected electrons are trapped at the $\mathrm{Si}_{3} \mathrm{~N}_{4} / \mathrm{Al}_{2} \mathrm{O}_{3}$ interface and thus lower the leakage current. The sample performs best because there is an additional barrier provided by $\mathrm{Al}_{2} \mathrm{O}_{3}$ to suppress the detrapping of electrons in $\mathrm{HfO}_{2}$. 
Figure 10. The C-V hysteresis of: (a) $5 \mathrm{~nm}$ and (b) $15 \mathrm{~nm}$-thick $\mathrm{Al}_{2} \mathrm{O}_{3}$ blocking oxide on the $5 \mathrm{~nm} \mathrm{La} 2 \mathrm{O}_{3}$ trap layer $/ 5 \mathrm{~nm} \mathrm{Al}_{2} \mathrm{O}_{3}$ tunnel oxide structure as a function of the double-sweep voltage. Reused with permission from [49], Copyright 2010, Materials Science in Semiconductor Processing.

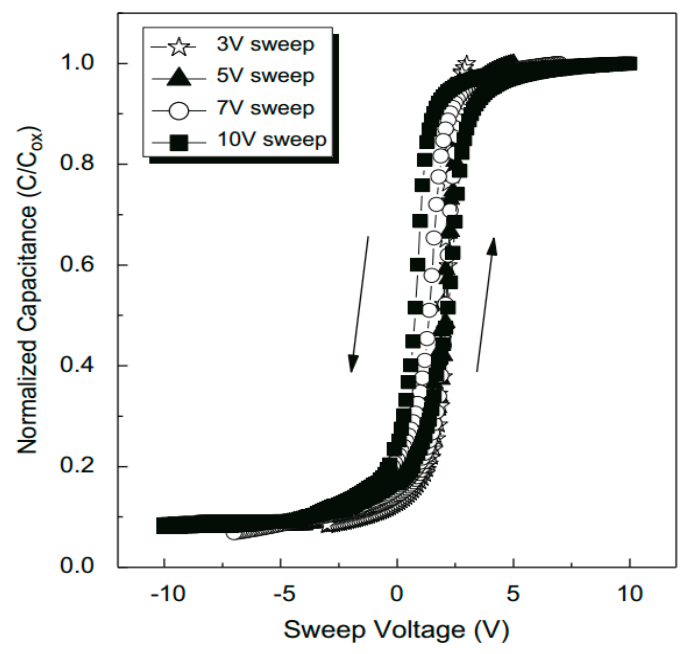

(a)

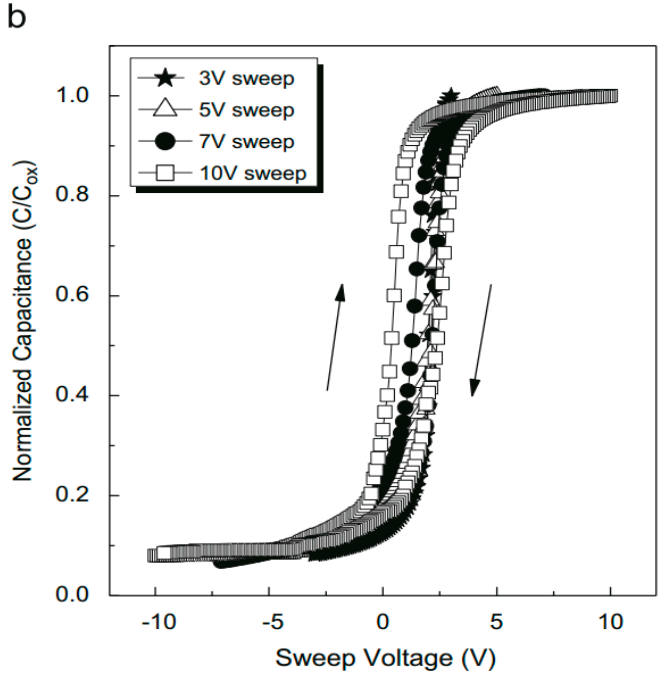

(b)

In conclusion, several groups' research output in the paper and the detailed specification and current status have been listed in a Table 3 (include high- $k$ as charge trapping layer, deposition technique, program/erase, endurance and retention characteristics). 
Table 3. Current research status of high- $k$ dielectrics as charge-trapping layer [37-50].

\begin{tabular}{|c|c|c|c|c|}
\hline $\begin{array}{l}\text { High- } k \text { as } \\
\text { CT Layer }\end{array}$ & Deposition Technique & $\begin{array}{c}\text { Program/Erase } \\
\text { Characteristic }\end{array}$ & Endurance Characteristics & $\begin{array}{c}\text { Retention } \\
\text { Characteristics } \\
\end{array}$ \\
\hline $\mathrm{Si}_{3} \mathrm{~N}_{4}+\mathrm{HfON}$ & $\begin{array}{l}\text { The layers of the TaN-[ }\left[\mathrm{SiO}_{2}-\mathrm{LaAlO}_{3}\right]-\left[\mathrm{Si}_{3} \mathrm{~N}_{4}-\mathrm{HfON}\right]-\left[\mathrm{LaAlO}_{3}-\right. \\
\left.\mathrm{SiO}_{2}\right]-\mathrm{Si} \text { devices comprised } 2.5 \mathrm{~nm} \text { of thermal } \mathrm{SiO}_{2}, 2.5 \mathrm{~nm} \text { of } \\
\text { PVD LaAlO } \\
\text { by LPCVD. Then } 8 \mathrm{~nm} \text { of reactive PVD } \mathrm{HfON}_{0.2} \text { and } 5 \mathrm{~nm} \text { of } \mathrm{Si}_{3} \mathrm{~N}_{4} \\
\text { and } 200 \mathrm{~nm} \text { TaN by PVD. This was followed by standard gate } \\
\text { definition, self-aligned P+ implantation and an RTA. }\end{array}$ & $\begin{array}{l}150^{\circ} \mathrm{C} \text { and } \pm 16 \mathrm{~V} \text { program/erase } \\
(\mathrm{P} / \mathrm{E}) \text {, the device showed } \mathrm{P} / \mathrm{E} \\
\text { speed of } 100 \mu \mathrm{s} \text {, an initial } \Delta V_{\text {th }} \\
\text { window of } 5.6 \mathrm{~V} \text {. }\end{array}$ & $\begin{array}{l}\text { a large } 10^{5} \text {-cycle window of } \\
4.9 \mathrm{~V} \text { and } 10^{3} \text {-cycled } 10 \text {-year } \\
\text { retention window of } 4.1 \mathrm{~V} \text {, } \\
\text { at } \pm 16 \mathrm{~V} 100 \mu \mathrm{s} / \mathrm{E} \text {. }\end{array}$ & $\begin{array}{l}\text { An initial } \Delta V_{\text {th }} \text { window of } \\
5.6 \mathrm{~V} \text { is set and later } \\
\text { extrapolated } 10 \text { year } \\
\text { retention of } 3.8 \mathrm{~V} \text {. }\end{array}$ \\
\hline $\mathrm{ZrON}$ & $\begin{array}{l}\mathrm{ZrON} \text { film was deposited in a reactive magnetron sputtering } \\
\text { system as the charge-trapping layer. To form the } \mathrm{ZrON} \text { film, a } \\
\text { pure } \mathrm{Zr} \text { target was sputtered in an oxygen (4-sccm)/nitrogen } \\
(12 \text {-sccm)/argon mixture ( } 24 \text {-sccm) gas ambient. A subsequent } \\
\text { annealing was performed on some as-deposited samples in a } \mathrm{N}_{2} \\
\text { ambient at } 600^{\circ} \mathrm{C} \text { for } 30 \mathrm{~min} \text {. }\end{array}$ & $\begin{array}{l}3.81 \mathrm{~V} \text { hysteresis memory } \\
\text { window by } \pm 7 \mathrm{~V} \text { P/E voltage and } \\
1.98 \mathrm{~V} \text { flat-band voltage shift by } \\
\text { programming at }+7 \mathrm{~V} \text { for } 10 \mathrm{~ms} \text {. }\end{array}$ & $\begin{array}{l}\text { negligible degradation of the } \\
\text { memory window up to } 10^{5} \mathrm{P} / \mathrm{E} \\
\text { cycles from the endurance } \\
\text { measurement, in which } \pm 7 \mathrm{~V} \\
\text { with } 10 \mathrm{~ms} \text { gate pulse-width used. }\end{array}$ & $\begin{array}{l}28.6 \% \text { charge loss } \\
\text { after ten-year operation } \\
\text { at } 85^{\circ} \mathrm{C} \text {. }\end{array}$ \\
\hline $\mathrm{HfO}_{2}$ & $\begin{array}{l}\text { After a growth of thermal oxide with a thickness of } 3 \mathrm{~nm} \text { at } \\
700{ }^{\circ} \mathrm{C} \text { in dry } \mathrm{O}_{2} \text { ambient, a deposition of } \mathrm{HfO}_{2} \text { layers ranging } \\
\text { from } 8 \text { to } 2 \mathrm{~nm} \text { was followed by atomic layered chemical vapor } \\
\text { deposition method at } 300{ }^{\circ} \mathrm{C} \text { to evaluate the effect of thickness } \\
\text { on the charge trapping and tunneling characteristics. }\end{array}$ & $\begin{array}{l}\text { The memory window for } 8 \mathrm{~nm} \\
\mathrm{HfO}_{2} \text { layer is } 1.5 \mathrm{~V} \text { at high } \\
\text { frequency of } 1 \mathrm{MHz} \text { and sweep } \\
\text { voltage of } \pm 5 \mathrm{~V} \text {. }\end{array}$ & insufficient data given. & $\begin{array}{l}\text { An initial memory } \\
\text { window of } 6.16 \mathrm{~V} \text {; after } \\
10 \text { years, the memory } \\
\text { window of } 4.26 \mathrm{~V} \text {. Charge } \\
\text { loss rate of } 30.8 \% \text {. }\end{array}$ \\
\hline $\mathrm{Hf}_{1-x-y} \mathrm{~N}_{x} \mathrm{O}_{y}$ & $\begin{array}{l}\text { A 9-nm } \mathrm{Hf}_{1-x-y} \mathrm{~N}_{x} \mathrm{O}_{y} \text { layer was deposited by reactive sputtering } \\
\text { under a mixed } \mathrm{O}_{2} \text { and } \mathrm{N}_{2} \text { conditions with different } \mathrm{O}_{2} / \mathrm{N}_{2} \text { ratios } \\
\text { to study the } \mathrm{N} \% \text { dependence of the MONOS device integrity. }\end{array}$ & $\begin{array}{l}\text { The } \mathrm{Hf}_{0.3} \mathrm{~N}_{0.2} \mathrm{O}_{0.5} \text { MONOS device } \\
\text { showed } \pm 9 \mathrm{~V} \text { P/E voltage, } 100 \mu \mathrm{s} \\
\mathrm{P} / \mathrm{E} \text { speed, large initial } 2.8 \mathrm{~V} \\
\text { memory window. }\end{array}$ & $\begin{array}{l}\text { memory windows of } 2.4 \mathrm{~V} \text { and } \\
1.7 \mathrm{~V} \text { after } 10^{5} \text { cycles at } \pm 9 \mathrm{~V} \\
100 \mu \mathrm{s} \mathrm{P} / \mathrm{E} \text { for } \mathrm{Hf}_{0.3} \mathrm{~N}_{0.2} \mathrm{O}_{0.5} \\
\text { devices and } \mathrm{Hf}_{0.35} \mathrm{~N}_{0.10} \mathrm{O}_{0.55} \\
\text { MONOS devices, respectively. }\end{array}$ & $\begin{array}{l}\text { a ten-year expected } \\
\text { retention of } 1.8 \mathrm{~V} \text { at } \\
85^{\circ} \mathrm{C} \text { or } 1.5 \mathrm{~V} \text { at } 125^{\circ} \mathrm{C} \text {. }\end{array}$ \\
\hline $\mathrm{HfAlO}_{2}$ & $\begin{array}{l}\text { For the } \mathrm{SOHOS} \text { device, pure } \mathrm{HfO}_{2} \text { and } \mathrm{Al}_{2} \mathrm{O}_{3} \text { films were } \\
\text { deposited by the } \mathrm{ALD} \text {, while } \mathrm{HfAlO} \text { films were deposited by } \\
\text { metal organic chemical vapor deposition using a single cocktail } \\
\text { source. The } \mathrm{Al}_{2} \mathrm{O}_{3} \text { concentration in } \mathrm{HfAlO} \text { was kept } \\
\text { at } 10 \% \text {. }\end{array}$ & $\begin{array}{l}\text { From the programming } \\
\left(V_{\mathrm{g}}-V_{\mathrm{fb}}=6 \mathrm{~V}\right) \text { and erasing } \\
\left(V_{\mathrm{g}}-V_{\mathrm{fb}}=-6 \mathrm{~V}\right) \text {, memory } \\
\text { window is } 3 \mathrm{~V} \text { at } 100 \mathrm{~ms} \text { of } \\
\mathrm{P} / \mathrm{E} \text { process. }\end{array}$ & $\begin{array}{l}\text { HfAlO devices show a } \\
\text { negligible degradation in the } \\
\text { threshold voltage window after } \\
10^{4} \mathrm{~W} / \mathrm{E} \text { cycles. }\end{array}$ & $\begin{array}{l}\text { The initial } V_{\mathrm{fb}} \text { after } \\
\text { programming is } 3.5 \mathrm{~V} \\
\text { for } 12.5 \mathrm{~nm} \text { HfAlO and } \\
\text { after } 10^{4} \mathrm{~s} \text { the value } \\
\text { retains at } 3.4 \mathrm{~V} \text {. }\end{array}$ \\
\hline
\end{tabular}


Table 3. Cont.

\begin{tabular}{|c|c|c|c|c|}
\hline $\begin{array}{l}\text { High- } k \text { as } \\
\text { CT Layer }\end{array}$ & Deposition Technique & $\begin{array}{c}\text { Program/Erase } \\
\text { Characteristic }\end{array}$ & Endurance Characteristics & $\begin{array}{c}\text { Retention } \\
\text { Characteristics }\end{array}$ \\
\hline $\mathrm{Y}_{2} \mathrm{O}_{3}$ & $\begin{array}{l}\text { A } 3 \mathrm{~nm} \mathrm{Y}_{2} \mathrm{O}_{3} \text { film was deposited on the tunneling oxide by } \\
\text { sputtering with yttrium target in a system with a base pressure } \\
\text { of } 9.8 \times 10^{-3} \mathrm{~m} \cdot \text { bar at room temperature. The sputtering } \\
\text { process was performed in diluted } \mathrm{O}_{2}\left(\mathrm{Ar} / \mathrm{O}_{2}=25 / 5\right) \text { ambient } \\
\text { sputtering power of } 100 \mathrm{~W} \text {, at sputter rates of about } \\
2.5 \AA / \mathrm{min} \text {. Rapid thermal process anneal of } 700{ }^{\circ} \mathrm{C} \text { in } \mathrm{N}_{2}, \mathrm{O}_{2} \text {, } \\
\text { or } \mathrm{N}_{2} \mathrm{O} \text { ambient for } 30 \mathrm{~s} \text { was then performed to transform } \\
\mathrm{Y}_{2} \mathrm{O}_{3} \text { film into Y-silicate charge trapping layer. }\end{array}$ & $\begin{array}{l}\text { For the condition of } V_{\mathrm{D}}=6 \mathrm{~V} \\
\text { and } V_{\mathrm{G}}=8 \mathrm{~V} \text { at } 1 \mathrm{~ms} \text {, a } \\
\text { high- } k \mathrm{Y}_{2} \mathrm{O}_{3} \text { SONOS-type } \\
\text { memory after } \mathrm{N}_{2} \text { annealing } \\
\text { exhibits a larger memory } \\
\text { window of } 2.43 \mathrm{~V} \text { compared } \\
\text { with other annealing gases. }\end{array}$ & $\begin{array}{l}\text { The values of } V_{\text {th }} \text { in the } \\
\text { program and erase states for } \\
\text { Y-silicate charge trapping } \\
\text { layer memory prepared at a } \\
\mathrm{N}_{2} \text { gas annealing did not } \\
\text { increase significantly up to } \\
10^{5} \mathrm{P} / \mathrm{E} \text { cycles. }\end{array}$ & $\begin{array}{l}\text { An yttrium silicate trapping storage } \\
\text { layer memory annealed in } \mathrm{N}_{2} \text { gas } \\
\text { exhibits a small charge loss of } \\
\text { about } 4 \% \text { measured time up to } 10^{4} \mathrm{~s} \\
\text { and at } 25^{\circ} \mathrm{C} \text {. At the temperature at } \\
125^{\circ} \mathrm{C} \text {, SONOS-type memory } \\
\text { prepared under an } \mathrm{Y}_{2} \mathrm{O}_{3} \text { trapping } \\
\text { layer and annealed in } \mathrm{N}_{2} \text { gas has a } \\
\text { lower charge loss of } 22 \% \text { during } \\
\text { the program state compared with } \\
\text { other annealing gases. }\end{array}$ \\
\hline $\mathrm{Tb}_{2} \mathrm{O}_{3}$ & $\begin{array}{l}\text { The } 8 \mathrm{~nm} \mathrm{~Tb} \mathrm{O}_{3} \text { film was deposited on the tunneling oxide by } \\
\text { reactive sputtering in diluted } \mathrm{O}_{2} \text { from a terbium target as a } \\
\text { charge trapping layer. The wafers were annealed in } \mathrm{O}_{2} \text { gas for } \\
30 \mathrm{~s} \text { at } 800{ }^{\circ} \mathrm{C} \text { by rapid thermal annealing. }\end{array}$ & $\begin{array}{l}\text { Threshold voltage shifting } \\
\text { (memory window of } 1.41 \mathrm{~V} \\
\text { operated at } V_{\mathrm{g}}=8 \mathrm{~V} \text { at } 0.1 \mathrm{~s} \text { ). }\end{array}$ & $\begin{array}{l}\text { The values of } V_{\mathrm{FB}} \text { in the } \\
\text { program and erase states did } \\
\text { not increase significantly up } \\
\text { to } 10^{5} \mathrm{P} / \mathrm{E} \text { cycles. }\end{array}$ & $\begin{array}{l}\text { Charge loss } 10 \% \text { measured time up } \\
\text { to } 10^{4} \text { s at } 85^{\circ} \mathrm{C} .\end{array}$ \\
\hline $\mathrm{Ta}_{2} \mathrm{O}_{5}$ & $\begin{array}{l}\text { After standard clean, the substrate was first annealed in } \mathrm{NH}_{3} \\
\text { at } 700{ }^{\circ} \mathrm{C}, 10 \mathrm{~s} \text { to improve interface quality, followed by } \mathrm{CVD} \\
\mathrm{HfO}_{2} \text { tunneling oxide layer formation using Hafnium } \\
\text { t-butoxide }\left(\mathrm{Hf}\left(\mathrm{OC}_{4} \mathrm{H}_{9}\right)_{4} \text { at } 500^{\circ} \mathrm{C} \text {. The } \mathrm{Ta}_{2} \mathrm{O}_{5} \text { charge-trapping }\right. \\
\text { layer was formed by oxidation of physical vapor deposition } \\
\text { (PVD) Ta at } 550^{\circ} \mathrm{C} \text {. }\end{array}$ & $\begin{array}{l}\text { Memory windows of about } \\
0.8 \mathrm{~V} \text { when the device is } \\
\text { programmed with } \pm 8 \mathrm{~V}-1-\mathrm{ms} \\
\text { gate pulse; The device can be } \\
\text { written starting from } 10 \text { us and } \\
\text { erased from } 1 \mathrm{~ms} \text { for } 6 \text { and } 7 \mathrm{~V} \text {. }\end{array}$ & $\begin{array}{l}\text { Memory window has no } \\
\text { obvious shrink after } \\
10 \text { write/erase cycles with } \\
8 \mathrm{~V} 1 \mathrm{~ms} \text { stress at room } \\
\text { temperature. }\end{array}$ & $\begin{array}{l}\text { Retention characteristics at room } \\
\text { temperature and } 85^{\circ} \mathrm{C} \text { demonstrate } \\
\text { a decay rate of } 50 \mathrm{mV} / \mathrm{dec} \text {. } \\
\text { Memory window extrapolated at } \\
\text { ten years is } 0.64 \mathrm{~V} \text { (initial } 0.8 \mathrm{~V} \text { ) } \\
\text { at room temperature, and } 0.42 \mathrm{~V} \\
\text { at } 85^{\circ} \mathrm{C} \text {. }\end{array}$ \\
\hline
\end{tabular}


Table 3. Cont

\begin{tabular}{|c|c|c|c|c|}
\hline $\begin{array}{l}\text { High- } k \text { as } \\
\text { CT Layer }\end{array}$ & Deposition Technique & $\begin{array}{l}\text { Program/Erase } \\
\text { Characteristic }\end{array}$ & Endurance Characteristics & $\begin{array}{c}\text { Retention } \\
\text { Characteristics }\end{array}$ \\
\hline $\mathrm{MoO}_{x}$ & $\begin{array}{l}\text { The embedded } \mathrm{MoO}_{x} \text { layer was sputtered from } \\
\text { the Mo target in } \mathrm{Ar} / \mathrm{O}_{2}(1: 1) \text { at } 5 \mathrm{mTorr} \text { and } \\
100 \mathrm{~W} \text { for } 15 \mathrm{~s} \text {. The as-deposited } \mathrm{MoO}_{x} \text { layer } \\
\text { was transformed into nanocrystalline } \mathrm{MoO}_{3} \text {, } \\
\text { after the PDA step at } 800^{\circ} \mathrm{C} \text { for } 1 \text { min in the } \\
\text { pure } \mathrm{N}_{2} \text { ambient by rapid thermal annealing. }\end{array}$ & $\begin{array}{l}\text { The nc- } \mathrm{MoO}_{x} \text { sample shows a large } V_{\mathrm{FB}} \\
\text { shift of }-0.52 \mathrm{~V} \text { after the }-8 \mathrm{~V} \text { stress, } \\
\text { which corresponds to the hole trapping } \\
\text { density of } 1.14 \times 10^{12} \mathrm{~cm}^{-2} \text {. On the } \\
\text { other hand, for the same sample, a very } \\
\text { small positive } V_{\mathrm{FB}} \text { shift, i.e., } 0.04 \mathrm{~V} \text { is } \\
\text { observed after the }+8 \mathrm{~V} \text { stress. }\end{array}$ & insufficient data given. & $\begin{array}{l}\text { About } 54 \% \text { of trapped holes } \\
\text { (under the }-8 \mathrm{~V} \text { stress condition) } \\
\text { remain in the sample after } 10 \text { years. } \\
\text { Also, about } 52 \% \text { of trapped holes } \\
\text { (under the }-7 \mathrm{~V} \text { stress condition) } \\
\text { remain in the sample after } 10 \text { years. }\end{array}$ \\
\hline $\mathrm{SrTiO}_{3}$ & $\begin{array}{l}3 \mathrm{~nm} \mathrm{SrTiO}_{3} \text { was deposited on the } \mathrm{SiO}_{2} \text { by } \\
\text { reactive sputtering using a } \mathrm{SrTiO}_{3} \text { target in a } \\
\text { mixed } \mathrm{Ar} / \mathrm{N}_{2}(4 / 1) \text { or } \mathrm{Ar} / \mathrm{O}_{2}(4 / 1) \text { ambient. }\end{array}$ & $\begin{array}{l}\text { memory window } \\
(8.4 \mathrm{~V} \text { at } \pm 10 \mathrm{~V} \text { sweeping voltage), } \\
\mathrm{P} / \mathrm{E} \text { speeds }(1.8 \mathrm{~V} \text { at } 1 \mathrm{~ms}+8 \mathrm{~V})\end{array}$ & $\begin{array}{l}\text { memory window after } 10^{5} \\
\text { cycles is } 2.13 \mathrm{~V} \text { compared with } \\
\text { initial value of } 2.07 \mathrm{~V} \text {. }\end{array}$ & charge loss of $38 \%$ after $10^{4} \mathrm{~s}$ \\
\hline $\mathrm{BaTiO}_{3}$ & $\begin{array}{l}10 \mathrm{~nm} \mathrm{Zr} \text {-doped } \mathrm{BaTiO}_{3} \text { was deposited on the } \\
\mathrm{SiO}_{2} \text { by reactive sputtering using } \mathrm{BaTiO}_{3} \text { and } \\
\mathrm{Zr} \text { targets in a mixed } \mathrm{Ar} / \mathrm{O}_{2} \text { ambient, and the } \\
\text { atomic ratio of } \mathrm{Zr} \text { and } \mathrm{Ti} \text { was determined to be } \\
1 / 3 \text {. The sample went through PDA in a } \mathrm{N}_{2} \\
\text { ambient at } 900{ }^{\circ} \mathrm{C} \text { for } 30 \mathrm{~s} \text {. }\end{array}$ & $\begin{array}{l}\text { memory window }(8.3 \mathrm{~V} \text { at } \pm 12 \mathrm{~V} \text { for } 1 \mathrm{~s}) \text {, } \\
\text { but higher program speed at low gate } \\
\text { voltage }(3.2 \mathrm{~V} \text { at } 100 \mu \mathrm{s}+6 \mathrm{~V})\end{array}$ & $\begin{array}{l}\text { Under a } \pm 12 \mathrm{~V} 100 \mu \text { s stress } \\
\text { pulse the P/E windows of the } \\
\text { Zr-BTO sample before and } \\
\text { after the } 10^{5} \text {-cycle stressing are } \\
6.4 \text { and } 6.6 \mathrm{~V} \text {, respectively, and } \\
\text { negligible degradation happens. }\end{array}$ & $\begin{array}{l}\text { charge loss of } 6.4 \% \text { at } 150^{\circ} \mathrm{C} \text { for } \\
10^{4} \mathrm{~s} .\end{array}$ \\
\hline $\begin{array}{l}\mathrm{Al}_{2} \mathrm{O}_{3}+ \\
\mathrm{La}_{2} \mathrm{O}_{3}+ \\
\mathrm{Al}_{2} \mathrm{O}_{3}\end{array}$ & $\begin{array}{l}\mathrm{Al}_{2} \mathrm{O}_{3} / \mathrm{La}_{2} \mathrm{O}_{3} / \mathrm{Al}_{2} \mathrm{O}_{3} \text { films were deposited on } \\
(100) \text { ntype } \mathrm{Si} \text { wafers (SILTRON, Korea) by a } \\
\text { MOCVD system. } \mathrm{N}_{2} \text { was used as a carrier gas } \\
\text { for La and } \mathrm{Al} \text { precursor. }\end{array}$ & $\begin{array}{l}\text { maximum memory window of this film } \\
\text { of about } 1.12 \mathrm{~V} \text { was observed at } 11 \mathrm{~V} \\
\text { for } 10 \mathrm{~ms} \text { in the program mode and at } \\
-13 \mathrm{~V} \text { for } 100 \mathrm{~ms} \text { in the erase mode. }\end{array}$ & $\begin{array}{l}\text { memory window after } 10^{4} \\
\text { cycles is } 1.2 \mathrm{~V} \text { compared with } \\
\text { initial value of } 1.12 \mathrm{~V} \text {. }\end{array}$ & insufficient data given. \\
\hline $\begin{array}{l}\mathrm{Si}_{3} \mathrm{~N}_{4}+ \\
\mathrm{Al}_{2} \mathrm{O}_{3}+ \\
\mathrm{HfO}_{2}\end{array}$ & $\begin{array}{l}\mathrm{Si}_{3} \mathrm{~N}_{4} \text { was deposited by low-pressure chemical } \\
\text { vapor deposition, and } \mathrm{Al}_{2} \mathrm{O}_{3} \text { and } \mathrm{HfO}_{2} \text { were } \\
\text { deposited using the metal-organic chemical } \\
\text { vapor deposition method. High-temperature } \\
\text { annealing was performed on all samples in a } \\
\mathrm{N}_{2} \text { ambient for } 30 \mathrm{~s} \text { at } 900{ }^{\circ} \mathrm{C} \text { by rapid } \\
\text { thermal anneal. }\end{array}$ & $\begin{array}{l}\text { at } V_{\mathrm{P}}=16 \mathrm{~V} \text { and } V_{\mathrm{E}}=-16 \mathrm{~V} \text { for } 1 \mathrm{~s}, \\
\text { memory window of this film of about } \\
10 \mathrm{~V}, \mathrm{P} / \mathrm{E} \text { speeds }(6.1 \mathrm{~V} \text { at } 1 \mathrm{~ms}+8 \mathrm{~V}) .\end{array}$ & no sufficient data given. & charge loss of $4 \%$ after $10^{4} \mathrm{~s}$. \\
\hline
\end{tabular}




\subsection{Blocking Layer}

$\mathrm{SiO}_{2}$ is the first dielectric as blocking layer in the flash memory. However, the large tunneling current through $\mathrm{SiO}_{2}$ is not acceptable upon continually scaling down of the dimensions of the flash memory. Since the erase speed for this type of SONOS devices is determined by the competition of the direct band-to-band tunneling current through a tunnel oxide and the unwanted Fowler-Nordheim tunneling current through a blocking oxide, the tunnel oxide thickness is fundamentally required to be less than $2 \mathrm{~nm}$ for a stable erase operation. Therefore, numerous attempts have been tried to replace thermal oxides by new dielectrics or related new structures.

Among the group III candidate dielectrics, such as alumina $\left(\mathrm{Al}_{2} \mathrm{O}_{3}\right)$, are very stable and robust materials, and have been extensively studied for many applications. Regarding its usefulness as an alternate gate dielectric, $\mathrm{Al}_{2} \mathrm{O}_{3}$ has many favorable properties, including a high band gap, thermodynamic stability on $\mathrm{Si}$ up to high temperatures, higher dielectric constant $(k \sim 9)$ than $\mathrm{SiO}_{2}$ $(k \sim 3.9)$, and is amorphous under the conditions of interest. In 2005, Lee proposed a $\mathrm{SiO}_{2} / \mathrm{SiN} / \mathrm{Al}_{2} \mathrm{O}_{3}$ (SANOS) device structure that can make fast P/E operation by FN tunneling mechanism possible even at a thicker tunnel oxide over $3 \mathrm{~nm}$ [51]. This is achieved by employing a high- $k$ dielectric material, especially $\mathrm{Al}_{2} \mathrm{O}_{3}$ replacing the top silicon oxide for a blocking layer. Electron injection is suppressed effectively by the $\mathrm{Al}_{2} \mathrm{O}_{3}$ and the leakage current characteristics of the $\mathrm{Al}_{2} \mathrm{O}_{3}$ layer are sufficient to block the electron injection from the gate in the reasonable erase voltage range. Furthermore, this structure achieves longer data retention and realizes lower voltage programming than the conventional $\mathrm{SiO}_{2} / \mathrm{SiN} / \mathrm{SiO}_{2}$ structure. Excellent retention characteristics could be achieved by using a thicker $(>2 \mathrm{~nm}$ ) tunnel oxide and thus, suppressing the electron discharging due to the band-to-band direct tunneling mechanism.

High- $k$ dielectrics as the blocking oxide layer proportionally reduced the electric field across the blocking oxide with its dielectric constant. Therefore, electron injection from the gate during erase can be effectively suppressed, which will generally in turn enhance the erase speed. In addition, using a physical thicker blocking layer film minimizes the electron leaking out to the gate during retention. Faster operation speed has been observed by replacing the $\mathrm{SiO}_{2}$ blocking layer with $\mathrm{Al}_{2} \mathrm{O}_{3}$. However, the drawback is that $\mathrm{Al}_{2} \mathrm{O}_{3}$ only has $k \sim 8-10$, and would therefore make it a relatively short-term solution for industry's needs $\sim 1-2$ generations. If no longer-term solution is available by the time that a replacement is required, however, such a short-term solution may indeed be suitable. Among all the high- $k$ dielectric candidates, rare earth oxides are recently of research interests as the gate dielectrics in CMOS applications, owing to their high- $k$ dielectric constant and large energy band gap. $\mathrm{Gd}_{2} \mathrm{O}_{3}$ has advantages as the blocking layer of the SONOS devices. One novel technique to engineer the $\operatorname{Gd}_{2} \mathrm{O}_{3}$ film was introduced by $\mathrm{Pu}$ et al., in 2009, for further improvement of the device performance [52]. Aluminum-doped $\mathrm{Gd}_{2} \mathrm{O}_{3}$ is an attractive dielectric material as the blocking oxide of SONOS-type Flash memory, showing a superior charge retention property, as well as the improved operation speed. The blocking oxide layer is $22 \%, 35 \%$, and $75 \% \mathrm{GdAlO}_{x}$ films (the entire stack EOTs are 10.8, 10.5, and $13 \mathrm{~nm}$, respectively). The physical thicknesses of the $22 \%, 35 \%$, and $75 \% \mathrm{GdAlO}_{x}$ layers are 14.9 , 11.1, and $14 \mathrm{~nm}$, and their calculated $k$ values are 17, 14, and 10, respectively. After gate stack patterning and source/drain implantation, dopant activation anneal was done at $850{ }^{\circ} \mathrm{C}$ for 30 min in a $\mathrm{N}_{2}$ ambient in a furnace tube. Forming gas $\left(10 \% \mathrm{H}_{2}\right.$ in $\left.\mathrm{N}_{2}\right)$ annealing at $420{ }^{\circ} \mathrm{C}$ for 10 min was added 
before wafer fab out. With a proper optimization of the structure, it has been shown that the $\mathrm{GdAlO}_{x}$ blocking layer can be a good candidate material for the further scaled charge-trap-type Flash memory devices.

Hafnium silicon oxide $(k \sim 12)$ has been evaluated as the blocking oxide recently. However, the devices exhibited a poor retention performance. Lanthanum-based dielectrics $\left(\mathrm{LaAlO}_{x}\right)$ are chosen as the blocking oxide due to their relatively large conduction band offset and high dielectric constant [53]. Compared to $\mathrm{Al}_{2} \mathrm{O}_{3}$ blocking oxide, $\mathrm{LaAlO}_{x}$ not only exhibits faster program speed, wider $V_{\text {th }}$ window, and more robustness to voltage stress but also has a better retention performance when the temperature is below $120^{\circ} \mathrm{C}$, particularly at $85^{\circ} \mathrm{C}$. It is also found that the retention property is critically determined by the conduction band offset of a blocking oxide, which is caused by the shallow trapping energy depth inside the nitride calculated to be $0.6-0.75 \mathrm{eV}$ below the conduction band edge. $\mathrm{LaAlO}_{x}$ blocking oxides were deposited using an atomic layer deposition method. During the ALD process, $\mathrm{La}(\mathrm{iPrCp})_{3}, \mathrm{Al}\left(\mathrm{CH}_{3}\right)_{3}$, and $\mathrm{H}_{2} \mathrm{O}$ were used as lanthanum precursor, aluminum precursor, and oxidant, respectively. After gate stack patterning, S/D implantation with arsenic, dopant activation annealing in a furnace $\left(850{ }^{\circ} \mathrm{C}\right.$ for $30 \mathrm{~min}$ in a $\mathrm{N}_{2}$ ambient), and forming gas anneal was performed at $420{ }^{\circ} \mathrm{C}$ for $30 \mathrm{~min}$ in a $\mathrm{N}_{2} / \mathrm{H}_{2}$ ambient. The physical thickness of LaAlO were $17 \mathrm{~nm}$, and they exhibit the same gate stack equivalent oxide thickness $\left(\mathrm{EOT}_{\text {total }}=12.2 \mathrm{~nm}\right)$. The atomic ratio of $\mathrm{La} /(\mathrm{La}+\mathrm{Al})$ in $\mathrm{LaAlO}_{x}$ film was around $55 \%$.

Among rare-earth metal oxides, yttrium oxide $\left(\mathrm{Y}_{2} \mathrm{O}_{3}\right)$ shows the strongest affinity for oxygen, no humidity absorption (compared with $\mathrm{La}_{2} \mathrm{O}_{3}$ ), and no magnetic characteristics (compared with $\mathrm{Gd}_{2} \mathrm{O}_{3}$ ), thus attracting increasing interest as a blocking layer. The main shortcomings of $\mathrm{Y}_{2} \mathrm{O}_{3}$ lie in its poor thermal property and relatively small band-gap $(\sim 6 \mathrm{eV})$ compared with $\mathrm{Al}_{2} \mathrm{O}_{3}$. A novel method to engineer $\mathrm{Y}$-doped $\mathrm{Al}_{2} \mathrm{O}_{3}$ film as the blocking layer was proposed by Huang et al., in 2011, via co-sputtering $\mathrm{Y}$ and $\mathrm{Al}$ targets in an $\mathrm{Ar} / \mathrm{O}_{2}$ mixed ambient for further improvement of the dielectric performance [54]. Compared with $\mathrm{Al}_{2} \mathrm{O}_{3}$ and $\mathrm{Y}_{2} \mathrm{O}_{3}$ films, the optimized $\mathrm{Y}_{x} \mathrm{Al}_{y} \mathrm{O}$ film shows lower interface-state density, lower bulk charge-trapping density, higher dielectric constant, and smaller gate leakage, due to the suppressed interlayer and good thermal property ascribed to appropriate $\mathrm{Y}$ and $\mathrm{Al}$ contents in the thin film. $\mathrm{Y}_{x} \mathrm{Al}_{y} \mathrm{O}$ with different $\mathrm{Y}$ contents was deposited on the wafers by co-sputtering of $\mathrm{Al}$ and $\mathrm{Y}$ targets in a mixed ambient $\left(\mathrm{Ar} / \mathrm{O}_{2}=24: 10\right)$. To explore the ability of $\mathrm{Y}$ doping to consume the interlayer, a high ratio of oxygen was used for the reactive sputtering because it could lead to a thicker interlayer. Al sputtering power was fixed at $25 \mathrm{~W}$, while Y sputtering power was set as 20, 25, and $30 \mathrm{~W}$ to obtain samples with different amounts of $\mathrm{Y}$ incorporation. Following that, the samples received post-deposition annealing (PDA) at $950{ }^{\circ} \mathrm{C}$ for $30 \mathrm{~s}$ in $\mathrm{N}_{2}$ ambient. All the samples had similar EOT ( 3.1 nm).

\subsection{Tunneling Layer}

There are two dominant charge-injection mechanisms available to change the charge content of the charge trapping memory: channel hot electron (CHE) and Fowler-Nordheim (F-N) tunneling. The fundamental of $\mathrm{CHE}$ is to provide enough energy to the channel electrons to overcome the tunnel oxide (silicon energy barrier). A large drain voltage induces a lateral electric field (between source and drain). This field increases the energy of the electrons, thus making them hot. The hot electrons are 
injected from the channel into the floating gate or the charge-trapping layer, due to the vertical electric field applied from the gate. The injection mainly happens near the drain area, where the electrons have maximum energy. Electron is injected because it has sufficient energy higher than the barrier, which means that it should not suffer too many scattering events which reduce its energy while it moves from the source to the drain. Since the probability of the case is quite low, the electron, which does satisfy these conditions, is regarded as lucky. This also implies that hot electron injection is an inefficient method of programming since only a tiny part of channel electrons is injected. Figure 11 describes a schematic energy band diagram of it.

Figure 11. A schematic energy band diagram describing the three processes involved in electron injection. Reused with permission from [34], Copyright 1997, IEEE.

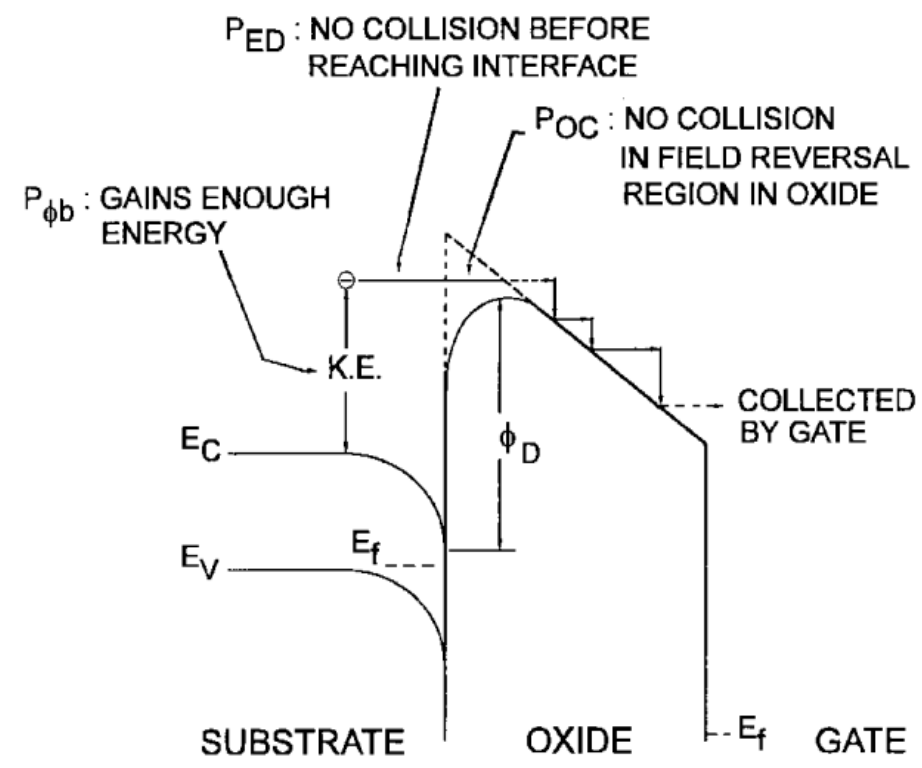

F-N tunneling refers to quantum-mechanical tunneling through a thin potential barrier, induced by an electric field. The oxide band bends under the application of an electric field, and presents a triangle-shaped barrier to the charge-trapping layer. The larger the electric field, the thinner the tunneling barrier is. Thus, more current occurs. F-N tunneling current is verified as a function of electric field and the current is exponentially dependent on the field. The probability of tunneling also depends on the distribution of carriers in the injecting material and the height of the barrier. Unlike the CHE discussed earlier, F-N tunneling injection is more efficient. Concerning the poor quality oxides that contain large numbers of bulk and interface traps, trap-assisted tunneling increases tunneling current density to much greater values, beyond expected, due to the effective decrease in the barrier. Figure 12 gives F-N tunneling of electrons from the poly-Si floating gate into the Si substrate. A table is also presented below (Table 4), including the advantages and disadvantages for the two charge injection mechanisms [34].

Originally, $\mathrm{SiO}_{2}$ is the tunneling layer in the SONOS structure on the Si substrate due to the largest band-gap among dielectrics, and, as the native oxide, the best interface quality as well as least oxide traps, thus lowest leakage current. For the consideration of reliability degradation issue, thermal oxide now is still dominant in charge trapping memory as tunneling layer. However, SONOS suffers from retention problems due to direct tunneling leakage through the thin tunnel oxide. For a conventional 
charge trapping memory device, it tends to have a thinner tunneling oxide for higher $\mathrm{P} / \mathrm{E}$ speeds and lower operating voltages, whereas a thinner tunneling oxide may deteriorate its retention property.

A band-gap engineered ONO tunneling dielectric was proposed by Lue et al., to replace the traditional tunnel oxide in SONOS, due to ultra-thin nitride $(<2 \mathrm{~nm})$ has negligible charge trapping [55]. This concept is demonstrated by a multilayer structure of $\mathrm{O} 1 / \mathrm{N} 1 / \mathrm{O} 2 / \mathrm{N} 2 / \mathrm{O} 3$, where the ultra-thin "O1/N1/O2" serves as a non-trapping tunneling dielectric, N2 the high-trapping-rate charge storage layer, and $\mathrm{O} 3$ the blocking oxide. The ultra-thin "O1/N1/O2" provides a "modulated tunneling barrier". Structure of the device is shown in Figure 13. It suppresses direct tunneling at low electric field during retention, while it allows efficient hole tunneling erase at high electric field due to the band offset. The ONO tunneling dielectric serves as an efficient hole tunneling barrier for SONOS, and it is much more reliable and practical. Therefore, this SONOS offers fast hole tunneling erase, while it is immune to the retention problem of the conventional SONOS. The O1/N1/O2 tunneling dielectric consists of ultra-thin oxide $(\mathrm{O} 1: 1.5 \mathrm{~nm}, \mathrm{O} 2: 1.8 \mathrm{~nm})$ and nitride $(2 \mathrm{~nm})$. The thicker $(7 \mathrm{~nm}) \mathrm{N} 2$ serves as the charge-trapping layer and $\mathrm{O} 3(9 \mathrm{~nm})$ serves as the blocking oxide. $\mathrm{O} 3$ is grown by thermal conversion of $\mathrm{N} 2$ so that efficient interfacial traps between $\mathrm{N} 2 / \mathrm{O} 3$ are provided.

Figure 12. F-N tunneling of electrons from the poly-Si FG into the Si substrate through the triangular energy barrier posed by the tunneling layer. Reused with permission from [34], Copyright 1997, IEEE.

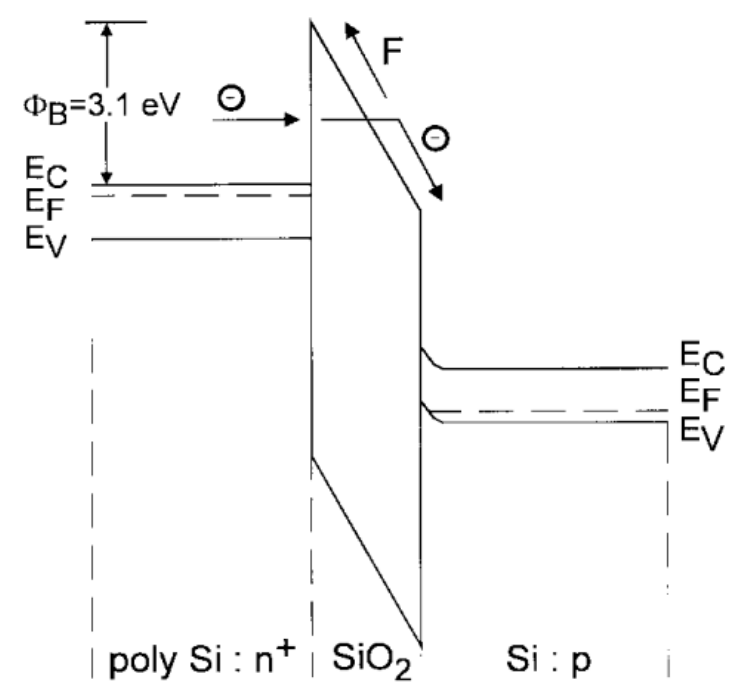

Figure 13. Structure of the n-channel BE-SONOS using ultra-thin ONO tunneling dielectric. Reused with permission from [55], Copyright 2003, IEEE.

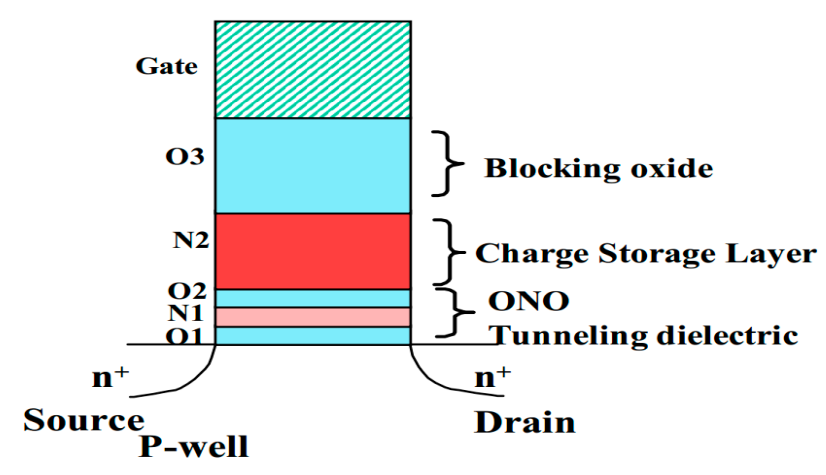


Table 4. Comparison between charge injection mechanisms [34].

Channel Hot Electron (CHE)

The physical mechanism of CHE is relatively simple to understand qualitatively. An electron traveling from the source to the drain gains energy from the lateral electric field and loses energy to the lattice vibrations.

At low fields, this is a dynamic equilibrium condition, which holds until the field strength reaches approximately $100 \mathrm{kV} / \mathrm{cm}$. For fields

Advantage exceeding this value, electrons are no longer in equilibrium with the lattice, and their energy relative to the conduction band edge begins to increase.

A lateral electric field (between source and drain) "heats" the electrons and a transversal electric field (between channel and control gate) injects the carriers through the oxide. The programming speed of CHE for conventional floating gate memory is faster.

The probability of the injecting electrons is quite low and hot electron injection is an inefficient method of programming. For an electron to overcome the potential barrier, three requirements must be meet accordingly:

1. The carrier has to be "lucky" enough to acquire enough energy from the lateral electric field to overcome the oxide barrier and to retain its energy after the collision that redirects the electron toward the interface $P_{\Phi \mathrm{b}}$.

2. The carrier follows a collision-free path from the redirection point to the interface $P_{\mathrm{ED}}$.

3. The carrier can surmount the repulsive oxide field at the injection point, due to the Schottky barrier lowering effect, without suffering an energy-robbing collision in the oxide $P_{\mathrm{OC}}$.

\section{Fowler-Nordheim (F-N)}

The F-N mechanism is widely used in NVM, particularly in EEPROM. With a relatively thick oxide $(20-30 \mathrm{~nm})$ one must apply a high voltage $(20-30 \mathrm{~V})$ to have an appreciable tunnel current. With thin oxides, the same current can be obtained by applying a much lower voltage. An optimum thickness is chosen in present devices, which use the tunneling phenomenon to tradeoff between performance constraints (programming speed, power consumption, etc.) and reliability concerns. There are three main reasons for this choice:

1. Tunneling is a pure electrical mechanism.

2. The involved current level is quite low and thus allows the internal generation of supply voltages needed for all operations.

3. It allows one to obtain the time to program $(<1 \mathrm{~ms}) 12$ orders of magnitude shorter than retention time $(>10 y)$, which is a fundamental request for all NVM technologies.

The exponential dependence of tunnel current on the oxide-electric field causes some critical problems of process control because. Very small variation of oxide thickness among the cells in a memory array produces a great difference in programming or erasing currents.

Bad quality oxides are rich of interface and bulk traps, and trap-assisted tunneling is made possible since the equivalent barrier height seen by electrons is reduced and tunneling requires a much lower oxide field than $10 \mathrm{MV} / \mathrm{cm}$.

The oxide defects must be avoided to control program/erase characteristics and to have good reliability. Frequent program and erase operations induce an increase of trapped charge in the oxide. This affects the barrier height, which is lower in the case of positive and higher in the case of negative trapping, respectively, thus increasing or decreasing the tunnel currents. 
A novel multilayer tunnel barrier concept was proposed consisting of a two-layer dielectrics stack with a low- $k$ /high- $k$ combination (or three-layer stack with a low- $k$ /high- $k /$ low- $k$ sequence in its symmetric form) that allows for either lower voltage or higher speed programming due to the increased current-voltage (I-V) slope [56]. Furthermore, its implementation is compatible with the high- $k$ dielectrics considered for $\mathrm{SiO}_{2}$ replacement in sub-100 nm CMOS technologies and represents a viable alternative for low-voltage low-power sub-100 nm NVM nodes. A barrier thinning of the stack was noticed and, in this sense, the stack can be regarded as a VARIable Oxide Thickness (VARIOT) dielectric. Alternatively, lower voltage programming at identical speed is possible. The thicker physical thickness of the stack offers better retention as compared to the EOT layer at low biases. An $8 \mathrm{~nm} \mathrm{SiO}$ (assumed as low- $k$ ) layer would satisfy the retention requirements for biases up to $3.6 \mathrm{~V}$, whereas FN programming in $100 \mu$ s would be achieved at nearly $10 \mathrm{~V}$. For $5 \mathrm{~nm} \mathrm{SiO} 2$ thickness, the programming bias decreases to $5.6 \mathrm{~V}$, whereas the maximum bias during retention decreases to nearly $1.5 \mathrm{~V}$. By contrast, in a two-layer $\mathrm{SiO}_{2} / \mathrm{Al}_{2} \mathrm{O}_{3}$ stack of the same EOT and with $2 \mathrm{~nm} \mathrm{SiO}$, the retention condition is satisfied for stack biases as high as $3 \mathrm{~V}$, whereas programming in $100 \mu$ s can be achieved at virtually the same bias as for the EOT layer. A symmetric structure with the same material combination (1.6 $\mathrm{nm} \mathrm{SiO}$ on each side) merely results in a slight performance decrease, allowing for both program and erase operations at comparable speeds. If voltage decrease is the prime issue, a two-layer stack (e.g., $\mathrm{SiO}_{2} / \mathrm{ZrO}_{2}$ with $1 \mathrm{~nm} \mathrm{SiO}_{2}$ ) with the second layer having an even higher $k$ value lows for very low-voltage programming. Therefore, it is concluded that for the same voltage, a shorter tunnel path of charges from the substrate to the charge-trapping layer is able to be obtained for the structure. Alternatively, a lower operating voltage can be achieved for the structure in order to obtain the same electric field across the tunneling layer as for the $\mathrm{SiO}_{2}$ structure.

\section{Conclusions}

Flash memories are ubiquitous in their use as portable storage media in cell phones, cameras, music players, and other portable electronic devices. Flash memory device, consisting of a charge-trapping transistor cell, is the most aggressively scaled electronic device, as evidenced by ever-increasing memory capacities. In this paper, we examine possible problems arising from continued scaling of these structures, and discuss novel solutions with high- $k$ dielectric to overcome them. Combining ultra-thin tunneling layer, high- $k$ dielectric charge-trapping layer, and large barrier height blocking layer, we enable the updated charge trapping memory cell as a scalable candidate for the next-generation technology. Every potential candidate has its own features and it might improve the related specification for charge trapping memory's performance at the cost of other issues, like fabrication technique, reliability degradation, scaling limitation or mass production cost. In general, some of the future research direction might be investigated. Tunnel oxide thickness scaling has essentially stopped. Work on barrier-engineered layers is an important area that has potential. The process steps involved in the planar floating-gate device need to be further optimized. For example, there needs to be better understanding for deposition of high quality high- $k$ dielectrics on metals, and interaction of the metal-tunnel oxide interface. As the cells become smaller and smaller, they will be limited by the number of electrons stored. At that point, instead of scaling cell-area, it is better to integrate cells in 3D to increase density. Work towards this, like the bit cost scalable (BiCS) cell, is an important direction 
of research. At those ultra-small dimensions, as the flash cell becomes intrinsically limited, some advanced non-charge based cells like FeRAM, MRAM, PCRAM, and ReRAM are also regarded as promising alternatives.

\section{Acknowledgments}

This research was funded in part from the Engineering and Physical Science Research Council of UK under the grant EP/D068606/1, the National Natural and Science Foundation of China under the grant No. 60976075 and 11375146, the Suzhou Science and Technology Bureau of China under the grant SYG201007 and SYG201223, and the Jiangsu Provincial Science and Technology Supporting Program under the grant BK2012636.

\section{Author Contributions}

The manuscript has been completed by Chun Zhao and Ce Zhou Zhao. Thanks to the contribution of the other authors. Ce Zhou Zhao also led the whole project related to the manuscript. Stephen Taylor and Paul R. Chalker have been mainly involved in the analysis and discussion.

\section{Conflicts of Interest}

The authors declare no conflict of interest.

\section{References}

1. She, M.; King, T.-J.; Hu, C.M.; Zhu, W.J.; Luo, Z.J.; Han, J.-P.; Ma, T.-P. JVD silicon nitride as tunnel dielectric in p-channel flash memory. IEEE Electron Device Lett. 2002, 23, 91-93.

2. Ma, T.P.; Han, J.P. Why is nonvolatile ferroelectric memory field-effect transistor still elusive? IEEE Electron Device Lett. 2002, 23, 386-388.

3. Lee, C.H.; Park, K.C.; Kim, K. Charge-trapping memory cell of $\mathrm{SiO}_{2} / \mathrm{SiN} /$ high- $k$ dielectric $\mathrm{Al}_{2} \mathrm{O}_{3}$ with TaN metal gate for suppressing backward-tunneling effect. Appl. Phys. Lett. 2005, 87, 073510:1-073510:3.

4. Zhang, G.; Wang, L.-K.; Won, J.Y.; Li, M.-F. Spatial distribution of charge traps in a SONOS-type flash memory using a high- $k$ trapping layer. IEEE Trans. Electron Devices 2007, 54, 3317-3324.

5. Yoshimitsu, Y.; Yoshinari, K.; Toshimasa, M. Scalable Virtual-Ground Multilevel-Cell Floating-Gate Flash Memory. IEEE Trans. Electron Devices 2013, 60, 2518-2524.

6. Lu, C.-Y.; Hsieh, K.-Y.; Liu, R. Future challenges of flash memory technologies. Microelectron. Eng. 2009, 86, 283-286.

7. Zhao, C.Z.; Zhang, J.F.; Zahid, M.B.; Groeseneken, G.; Degraeve, R.; de Gendt, S. Impact of gate materials on positive charge formation in $\mathrm{HfO}_{2} / \mathrm{SiO}_{2}$ stacks. Appl. Phys. Lett. 2006, 89, 023507:1-023507:3.

8. Ishiwara, H. Current status of ferroelectric-gate Si transistors and challenge to ferroelectric-gate CNT transistors. Curr. Appl. Phys. 2009, 9, S2-S6.

9. Fitsilis, M.; Mustafa, Y.; Waser, R. Scaling the ferroelectric field effect transistor. Integr. Ferroelectr. Int. J. 2005, 70, 29-44. 
10. Rueckes, T.; Kim, K.; Joselevich, E.; Tseng, G.Y.; Cheung, C.-L.; Lieber, C.M. Carbon nanotube-based nonvolatile random access memory for molecular computing. Science 2000, 289, 94-97.

11. Choi, W.Y.; Osabe, T.; Liu, T.-S. Nano-electro-mechanical nonvolatile memory (NEMory) cell design and scaling. IEEE Trans. Electron Devices 2008, 55, 3482-3488.

12. Kryder, M.H.; Kim, C.S. After hard drives-What comes next? IEEE Trans. Magn.2009, 45, 3406-3413.

13. Pagnia, H.; Sotnik, N. Bistable switching in electroformed metal-insulator-metal devices. Phys. Status Solidi 1988, 108, 11-65.

14. Jung, Y.; Yang, C.Y.; Lee, S.H.; Agarwal, R. Phase-change Ge-Sb nanowires: Synthesis, memory switching, and phase-instability. Nano Lett. 2009, 9, 2103-2108.

15. Waser, R.; Aono, M. Nanoionics-based resistive switching memories. Nat. Mater. 2007, 6, 833-840.

16. Scott, J.C.; Bozano, L.D. Nonvolatile memory elements based on organic materials. Adv. Mater. 2007, 19, 1452-1463.

17. Brewer, J.; Gill, M. Nonvolatile Memory Technologies with Emphasis on Flash: A Comprehensive Guide to Understanding and Using NVSM Devices; IEEE Press: Piscataway, NJ, USA, 2008.

18. International Technology Roadmap for Semiconductors: Process Integration, Devices and Structures, 2009. Available online: http://www.itrs.net/Links/2009ITRS/Home2009.htm (accessed on 14 July 2014).

19. De Salvo, B. Silicon Non-Volatile Memories: Paths of Innovation; John Wiley \& Sons: Hoboken, NJ, USA, 2010.

20. Zhao, Y. Design of higher- $k$ and more stable rare earth oxides as gate dielectrics for advanced CMOS devices. Materials 2012, 5, 1413-1438.

21. Tao, J.; Zhao, C.Z.; Zhao, C.; Taechakumput, P.; Werner, M.; Taylor, S.; Chalker, P.R. Extrinsic and intrinsic frequency dispersion of high-k materials in Capacitance-Voltage measurements. Materials 2012, 5, 1005-1032.

22. Suzuki, M. Comprehensive study of lanthanum aluminate high-dielectric-constant gate oxides for advanced CMOS devices. Materials 2012, 5, 443-477.

23. Miyata, N. Study of direct-contact HfO2/Si Interfaces. Materials 2012, 5, 512-527.

24. Zhao, C.; Zhao, C.Z.; Werner, M.; Taylor, S.; Chalker, P.R. Dielectric relaxation of high- $k$ oxides. Nanoscale Res. Lett. 2013, 8, 1-12.

25. Zhao, C.; Zhao, C.Z.; Werner, M.; Taylor, S.; Chalker, P.R.; King, P. Grain size dependence of dielectric relaxation in cerium oxide as high- $k$ layer. Nanoscale Res. Lett. 2013, 8, doi:10.1186/1556-276X-8-172.

26. Zhao, C.; Zhao, C.Z.; Tao, J.; Werner, M.; Taylor, S.; Chalker, P.R. Dielectric relaxation of lanthanide-based ternary oxides: Physical and mathematical models. J. Nanomater. 2012, 2012, doi:10.1155/2012/241470.

27. Zhao, C.; Zhao, C.Z.; Werner, M.; Taylor, S.; Chalker, P.R. Advanced CMOS gate stack: Present research progress. ISRN Nanotechnol. 2012, 2012, doi:10.5402/2012/689023. 
28. Zhao, C.Z.; Werner, M.; Taylor, S.; Chalker, P.R.; Jones, A.C.; Zhao, C. Dielectric aelaxation of la-doped zirconia caused by annealing ambient. Nanoscale Res. Lett. 2011, 6, doi:10.1007/s11671-010-9782-z.

29. Dai, M.-K.; Lin, T.-Y.; Yang, M.-H.; Lee, C.-K.; Huang, C.-C.; Chen, Y.-F. High-performance organic nano-floating-gate memory devices based on graphite nanocrystals as charge-trapping elements and high- $k \mathrm{Ta}_{2} \mathrm{O}_{5}$ as a controlled gate dielectric. J. Mater. Chem. C 2014, 2, 5342-5349.

30. Cao, Z.-Y.; Li, A.-D.; Li, X.; Cao, Y.-Q.; Wu, D. Ti-Al-O nanocrystal charge trapping memory cells fabricated by atomic layer deposition. Thin Solid Films 2014, 563, 6-9.

31. Ozaki, S.; Kato, T.; Kawae, T.; Morimoto, A. Influences of low-temperature postdeposition annealing on memory properties of $\mathrm{Al} / \mathrm{Al}_{2} \mathrm{O}_{3} / \mathrm{Al}$-rich $\mathrm{Al}-\mathrm{O} / \mathrm{SiO}_{2} / \mathrm{p}-\mathrm{Si}$ charge trapping flash memory structures. J. Vac. Sci. Technol. B 2014, 32, 031213:1-031213:5.

32. Zhu, H.; Bonevich, J.E.; Li, H.; Richter, C.A.; Yuan, H.; Kirilov, O.; Li, Q. Discrete charge states in nanowire flash memory with multiple $\mathrm{Ta}_{2} \mathrm{O}_{5}$ charge-trapping stacks. Appl. Phys. Lett. 2014, 104, doi:10.1063/1.4883717.

33. Leong, W.L.; Mathews, N.; Tan, B.; Vaidyanathan, S.; Dotz, F.; Mhaisalker, S. Towards printable organic thin film transistor based flash memory devices. J. Mater. Chem., 2011, 21, 5203-5214.

34. Pavan, P.; Bez, R.; Olivo, P.; Zanoni, E. Flash Memory Cells-An Overview. Proc. IEEE 1997, $85,1248-1271$.

35. Keenney, S.; Bez, R.; Cantarelli, D.; Piccinini, F.; Mathewson, A.; Lombardi, C. Complete transient simulation of Flash EEPROM devices. IEEE Trans. Electron Devices 1992, 39, 2750-2757.

36. Bez, R.; Camerlenghi, E.; Modelli, A.; Visconti, A. Introduction to FLASH memory. Proc. IEEE 2003, 91, 489-502.

37. Wu, Y.H.; Chen, L.L.; Wu, J.R.; Wu, M.L.; Lin, C.C.; Chang, C.H. Nonvolatile memory with nitrogen-stabilized cubic-phase $\mathrm{ZrO}_{2}$ as charge-trapping layer. IEEE Electron Device Lett. 2010, $31,1008-1010$.

38. White, M.H.; Adams, D.A.; Bu, J. On the go with SONOS. IEEE Circuits Devices Mag. 2000, 16, $22-31$.

39. Lin, S.H.; Chin, A.; Yeh, F.S.; McAlister, S.P. Good $150{ }^{\circ} \mathrm{C}$ retention and fast erase charge-crapping-engineered memory with scaled $\mathrm{Si}_{3} \mathrm{~N}_{4}$. In proceedings of IEEE International Electron Devices Meeting, San Francisco, CA, USA, 15-17 December 2008; pp. 1-4.

40. You, H.-W.; Cho, W.-J. Charge trapping properties of the $\mathrm{HfO} 2$ layer with various thicknesses for charge trap flash memory applications. Appl. Phys. Lett. 2010, 96, 093506:1-093506:3.

41. Yang, H.J.; Cheng, C.F.; Chen, W.B.; Lin, S.H.; Yeh, F.S.; McAlister, S.P.; Chin, A. Comparison of MONOS memory device integrity when using $\mathrm{Hf}_{1-x-y} \mathrm{~N}_{x} \mathrm{O}_{y}$ trapping layers with different $\mathrm{N}$ compositions. IEEE Trans. Electron Devices 2008, 55, 1417-1423.

42. Tan, Y.N.; Chim, W.K.; Choi, W.K.; Joo, M.S.; Byung, J.C. Hafnium aluminum oxide as charge storage and blocking-oxide layers in SONOS type nonvolatile memory for high-speed operation. IEEE Trans. Electron Devices 2006, 53, 654-662.

43. Pan, T.-M.; Yeh, W.-W. High-performance high- $k \mathrm{Y}_{2} \mathrm{O}_{3}$ SONOS-type flash memory. IEEE Trans. Electron Devices 2008, 55, 2354-2360.

44. Pan, T.-M.; Jung, J.-S.; Chen, F.-H. Metal-oxide-high-k-oxide-silicon memory structure incorporating a $\mathrm{Tb}_{2} \mathrm{O}_{3}$ charge trapping layer. Appl. Phys. Lett. 2010, 97, 012906:1-012906:3. 
45. Wang, X.; Liu, J.; Bai, W.; Kwong, D.-L. A novel MONOS-type nonvolatile memory using high- $k$ dielectrics for improved data retention and programming speed. IEEE Trans. Electron Devices 2004, 51, 597-602.

46. Liu, X.; Yang, C.H.; Kuo, Y.; Yuan, T. Nanocrystalline MoOx Embedded ZrHfO High $k$ Memories Charge Trapping and Retention Characteristics. ECS Trans. 2012, 45, 203-209.

47. Huang, X.D.; Lai, P.T.; Liu, L.; Xu, J.P. Nitrided $\mathrm{SrTiO}_{3}$ as charge-trapping layer for nonvolatile memory applications. Appl. Phys. Lett. 2011, 98, doi:10.1063/1.3601473.

48. Huang, X.D.; Sin, J.K.O.; Lai, P.T. Improved Charge-Trapping Characteristics of $\mathrm{BaTiO}_{3}$ by $\mathrm{Zr}$ Doping for Nonvolatile Memory Applications. IEEE Electron Device Lett. 2013, 34, 499-501.

49. Kim, J.H.; Cha, S.Y.; Choi, D.J. Memory characteristics of $\mathrm{Al}_{2} \mathrm{O}_{3} / \mathrm{La}_{2} \mathrm{O}_{3} / \mathrm{Al}_{2} \mathrm{O}_{3}$ multi-layer films with various blocking and tunnel oxide thicknesses. Mater. Sci. Semicond. Process. 2010, 13, 9-12.

50. Ye, Z.H.; Chang-liao, K.S.; Tsai, C.Y.; Tsai, T.T.; Wang, T.K. Enhanced Operation in Charge-Trapping Nonvolatile Memory Device With $\mathrm{Si}_{3} \mathrm{~N}_{4} / \mathrm{Al}_{2} \mathrm{O}_{3} / \mathrm{HfO} 2$ Charge-Trapping Layer. IEEE Electron Device Lett. 2012, 33, 1351-1353.

51. Lee, C.H.; Hur, S.H.; Shin, Y.C.; Choi, J.H.; Park, D.G.; Kim, K. Charge trapping device structure of $\mathrm{SiO}_{2} / \mathrm{SiN} /$ high- $k$ dielectric $\mathrm{Al}_{2} \mathrm{O}_{3}$ for high-density flash memory. Appl. Phys. Lett. 2005, 86, doi:10.1063/1.1897431.

52. Pu, J.; Chan, D.S.; Kim, S.-J.; Cho, B.J. Aluminum-doped gadolinium oxides as blocking layer for improved charge retention in charge-trap-type nonvolatile memory devices. IEEE Trans. Electron Devices 2009, 56, 2739-2745.

53. He, W.; Pu, J.; Chan, D.S.; Cho, B.J. Performance improvement in charge-trap flash memory using lanthanum-based high-k blocking oxide. IEEE Trans. Electron Devices 2009, 56, 2746-2751.

54. Huang, X.D.; Liu, L.; Xu, J.P.; Lai, P.T. Improved performance of yttrium-doped $\mathrm{Al}_{2} \mathrm{O}_{3}$ as inter-poly dielectric for flash-memory applications. IEEE Trans. Device Mater. Rel. 2011, 13, 490-494.

55. Lue, H.-T.; Wang, S.-Y.; Lai, E.-K.; Shih, Y.-H.; Lai, S.-C.; Yang, L.-W.; Chen, K.-C.; Ku, J.; Hsieh, K.-Y.; Liu, R.; et al. BE-SONOS: A bandgap engineered SONOS with excellent performance and reliability. In Proceedings of IEEE International IEDM Technical Digest Electron Devices Meeting, Washington, DC, USA, 5 December 2005; pp. 547-550.

56. Govoreanu, B.; Blomme, P.; Rosmeulen, M.; van Houdt, J.; de Meyer, K. VARIOT: A novel multilayer tunnel barrier concept for low voltage nonvolatile memory devices. IEEE Electron Device Lett. 2003, 24, 99-101.

(C) 2014 by the authors; licensee MDPI, Basel, Switzerland. This article is an open access article distributed under the terms and conditions of the Creative Commons Attribution license (http://creativecommons.org/licenses/by/3.0/). 